Florida International University FIU Digital Commons

\title{
An analysis of the South Florida commuter assistance program's implementation of transportation demand management initiatives
}

Elizabeth Carrera

Florida International University

DOI: $10.25148 /$ etd.FI14052585

Follow this and additional works at: https://digitalcommons.fiu.edu/etd

Part of the Environmental Sciences Commons

\section{Recommended Citation}

Carrera, Elizabeth, "An analysis of the South Florida commuter assistance program's implementation of transportation demand management initiatives" (2001). FIU Electronic Theses and Dissertations. 2055.

https://digitalcommons.fiu.edu/etd/2055 


\title{
FLORIDA INTERNATIONAL UNIVERSITY
}

Miami, Florida

\author{
AN ANALYSIS OF THE SOUTH FLORIDA \\ COMMUTER ASSISTANCE PROGRAM'S IMPLEMENTATION OF \\ TRANSPORTATION DEMAND MANAGEMENT INITIATIVES
}

A thesis submitted in partial fulfillment of the

requirements for the degree of

MASTER OF SCIENCE

in

ENVIRONMENTAL STUDIES

by

Elizabeth Carrera 
To: Dean Arthur W. Herriott

College of Arts and Sciences

This thesis, written by Elizabeth Carrera, and entitled An Analysis of the South Florida

Commuter Assistance Program's Implementation of Transportation Demand

Management Initiatives, having been approved in respect to style and intellectual content, is referred to you for judgment.

We have read this thesis and recommend that it be approved.

Mahadev Bhat

John Parker

Constantine Hadjilambrinos, Major Professor

Date of Defense: July 12, 2001

The thesis of Elizabeth Carrera is approved.

Dean Arthur W. Herriott College of Arts and Sciences

Dean Douglas Wartzok University Graduate School

Florida International University, 2001 


\section{DEDICATION}

I dedicate this thesis to: my loving and supportive parents who raised me to always depend upon myself to make it through life; my sister who always listened and cared about my doings from afar; my incredible friends, Lisa, Carey, Jenny, and Mary, who all encouraged me to stick with it during the rough times; to Patricia who encouraged me to go back to school while she embarked upon her own Ph.D. journey; and to my husband, Kirk, who had incredible patience in the end and made sure I was taken care of by cooking my dinners. Without their support and positive influence to embark upon this educational journey, the completion of my Masters degree would never have been possible. 


\section{ACKNOWLEDGMENTS}

I would like to thank the members of my committee for their support and understanding during the creation of this thesis. Dr. Constantine Hadjilambrinos was patient and supportive of me when I changed my thesis topic by helping me to quickly reformulate a topic. Dr. Mahadev Bhat guided me through the graduate process and has

supported me in encouraging me to finish my degree. Dr. Jack Parker has been a mentor to me since my Bachelors degree and continues to be a highly respected individual in my life.

I have found the Environmental Studies Graduate Program to be challenging and instrumental in the further expanding of my ideals for which I apply in my daily life and career. This experience has been and will be one of the most memorable in my life. 


\section{AN ANALYSIS OF THE SOUTH FLORIDA \\ COMMUTER ASSISTANCE PROGRAM'S IMPLEMENTATION OF \\ TRANSPORTATION DEMAND MANAGEMENT INITIATIVES \\ by}

Elizabeth Carrera

Florida International University, 2001

Miami, Florida

Professor Constantine Hadjilambrinos, Major Professor

The purpose of this study was to determine the effectiveness of implementing Transportation Demand Management (TDM) initiatives with the business community by the South Florida Commuter Assistance Program (CAP). To determine this effectiveness, the south Florida CAP was compared with the two other CAPs operating in the state, by analyzing independent evaluations of the program, and by conducting eight individual company case studies.

Independent evaluations of the south Florida CAP for the years $1997-2000$ were analyzed and found to have increasing trends in the number of companies adopting TDM initiatives. In addition, each case was selected from the numerous companies 
participating with the south Florida CAP. It was determined that companies with support from upper management adopted TDM initiatives more readily.

The findings demonstrated that the south Florida CAPs initiatives have been successful in working with the business community to adopt TDM initiatives. In its conclusions, the study offers further suggestions on what actions should be taken in the future to implement TDM initiatives. 


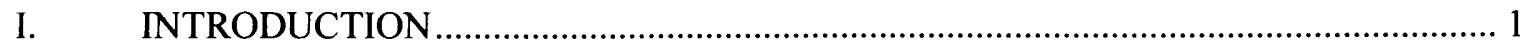

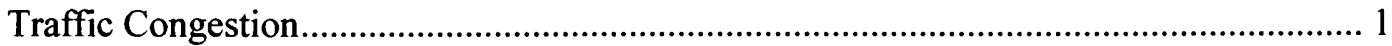

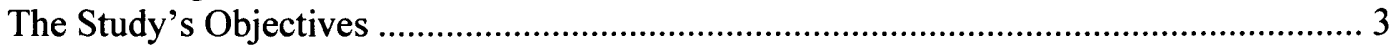

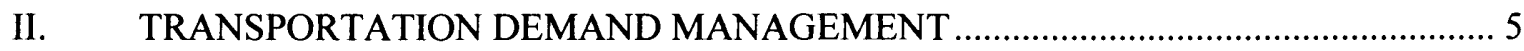

What is Transportation Demand Management? ............................................................... 5

A Historical Perspective ................................................................................................. 8

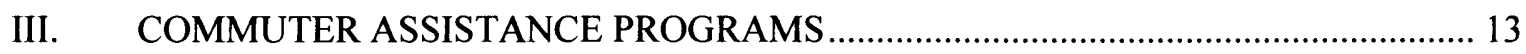

Defining a Commuter Assistance Program ........................................................................ 13

Commuter Services of North Florida ...................................................................... 14

Bay Area Commuter Services .................................................................................... 16

South Florida Commuter Services ....................................................................... 18

CSNF, BACS and SFCS Comparisons …………….................................................. 23

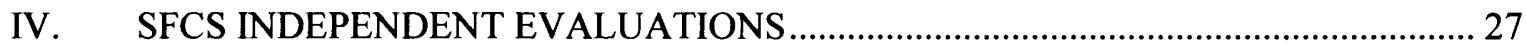

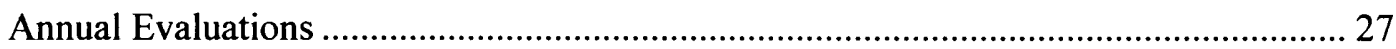

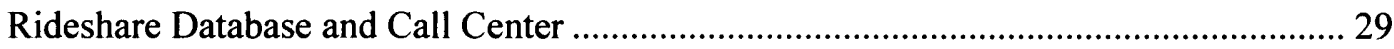

General Public Marketing and Outreach .................................................................. 30

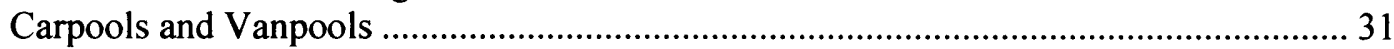

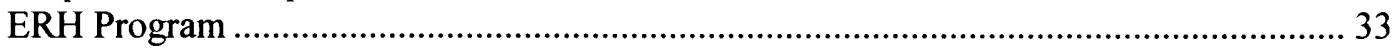

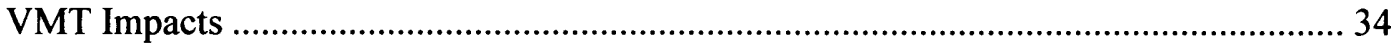

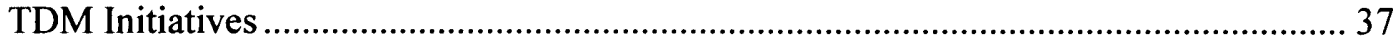

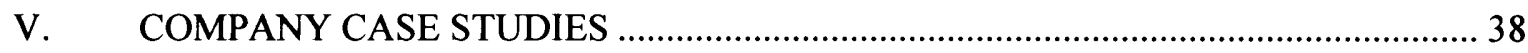

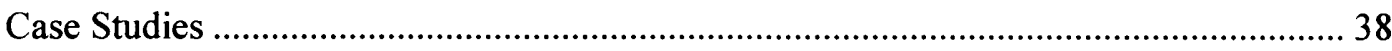

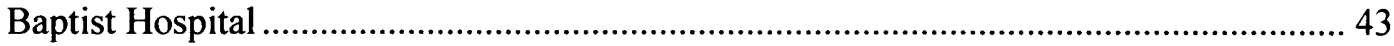

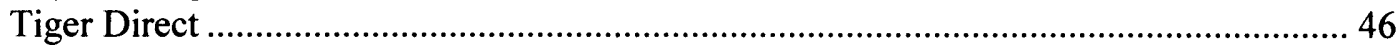

Royal Caribbean Cruise Lines....................................................................................... 49

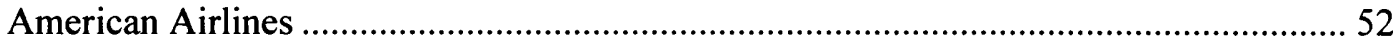

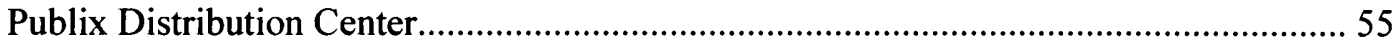

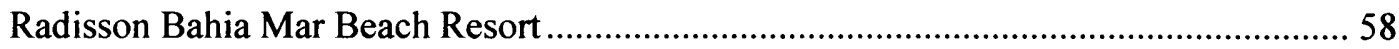

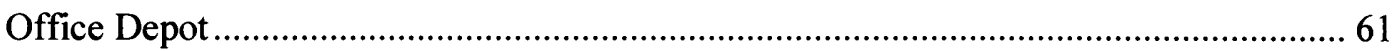

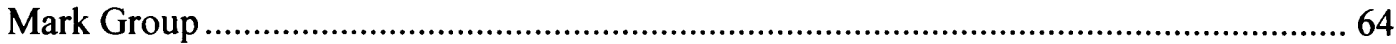

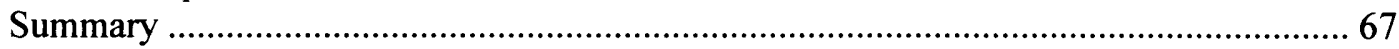

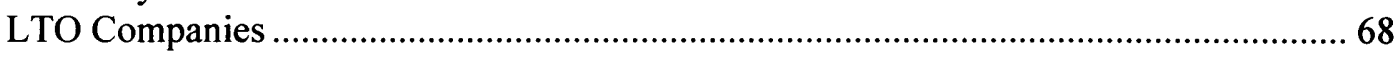

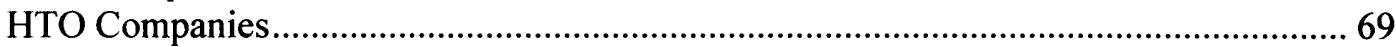

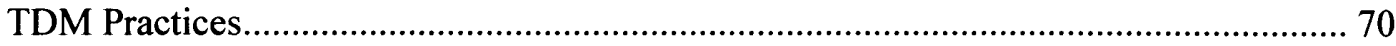

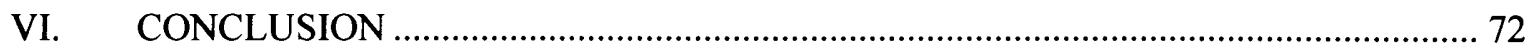

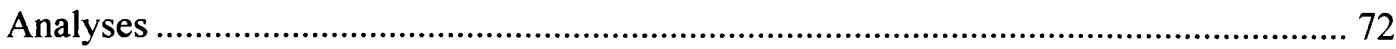

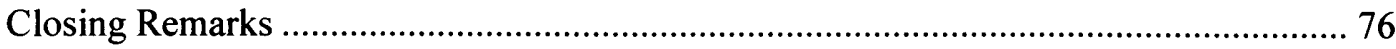

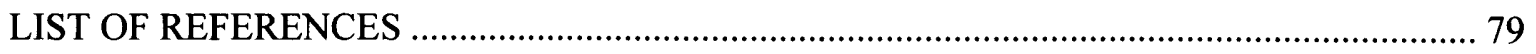


Table 1: Florida CAPs' Population and Applicant Per Capita 24

Table 2: Survey Methodology 27

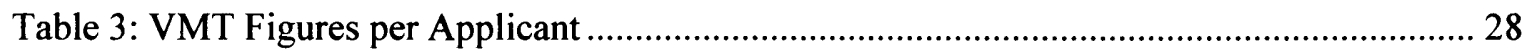

Table 4: Rideshare Database and Call Center Data........................................................... 29

Table 5: General Public Marketing and Outreach Data ....................................................... 31

Table 6: Carpooling and Vanpooling among Applicants Data.......................................... 33

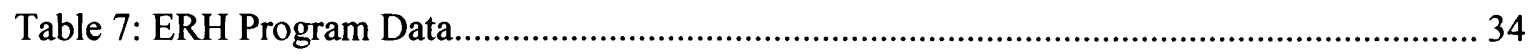

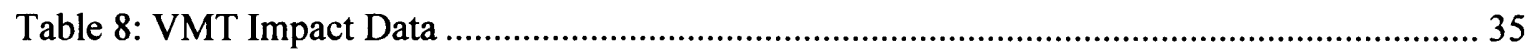

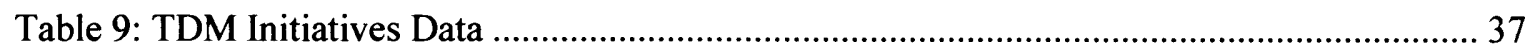

Table 10: Computing Average Commute Mileage.............................................................. 39

Table 11: Home and Work Mile Search Radii ............................................................... 40

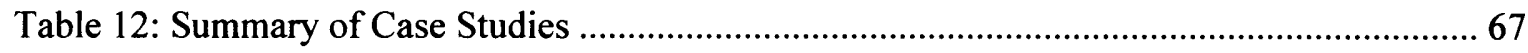

Table 13: TDM Initiatives for Case Study Companies ..................................................... 71 
Figure 1: Six WWII Posters Promoting Ridesharing ........................................................ 9

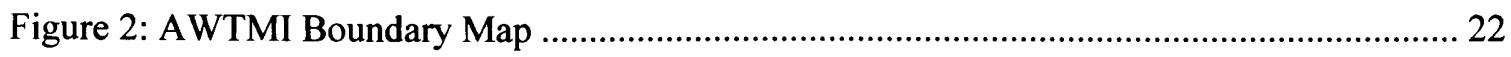

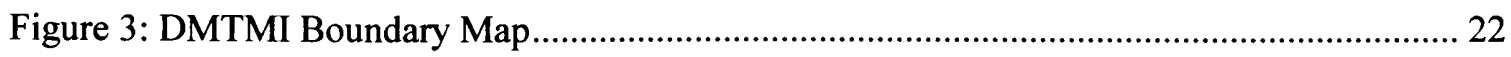

Figure 4: Baptist Hospital Applicants' Mode Percentages and Commute Miles ....................... 43

Figure 5: Baptist Hospital Applicant Distribution Map ................................................ 45

Figure 6: Tiger Direct Applicants' Mode Percentages and Commute Miles ........................... 46

Figure 7: Tiger Direct Applicant Distribution Map...................................................... 48

Figure 8: Royal Caribbean Applicants' Mode Percentages and Commute Miles ....................... 49

Figure 9: Royal Caribbean Applicant Distribution Map ................................................. 51

Figure 10: American Airlines Applicants' Mode Percentages and Commute Miles .................. 52

Figure 11: American Airlines Applicant Distribution Map................................................. 54

Figure 12: Publix DC Applicants' Mode Percentages and Commute Miles ............................. 55

Figure 13: Publix DC Applicant Distribution Map ....................................................... 57

Figure 14: Radisson Bahia Mar Applicants' Mode Percentages and Commute Miles ................ 58

Figure 15: Radisson Bahia Mar Applicant Distribution Map............................................. 60

Figure 16: Office Depot Applicants' Mode Percentages and Commute Miles .......................... 61

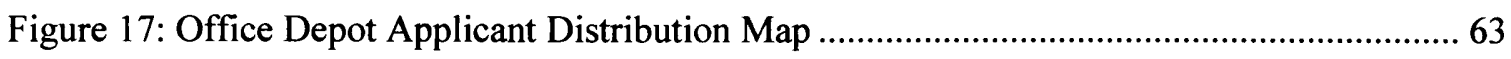

Figure 18: Mark Group Applicants' Mode Percentages and Commute Miles ............................ 64

Figure 19: Mark Group Applicant Distribution Map ...................................................... 66 


\section{Chapter 1}

\section{Introduction}

\section{Traffic Congestion}

Looking towards the future is a daunting task when envisioning an increase in traffic congestion in south Florida. As reported in the 2000 U.S. Census, Miami-Dade County ranked $21^{\text {st }}$ in the United States for congestion with Broward County ranking $38^{\text {th }}$. Traffic congestion has shown to have environmental, social and economic impacts on society. Consequences such as aggressive driving, foreign oil dependency, air pollution and land infringement are just a few that are prevalent in America.

As the number of licensed drivers and registered vehicles has increased, congestion often causes drivers to become frustrated leading to a more aggressive, high-risk driving style. According to the National Highway Traffic Safety Administration (NHTSA), aggressive drivers create an unsafe driving environment through their inconsiderate, self-centered driving (NHTSA, 1999). Drivers often commit multiple violations, including following too closely, changing lanes in an erratic or unsafe manner, signaling lane changes improperly, driving over the posted speed limit, and failing to obey traffic control devices. Because of these driving behaviors, hundreds of deaths, thousands of injuries and millions of dollars of property damage occur each year, and these behaviors contribute to the growing problems of hazardous traffic conditions and criminal acts related to aggressive driving.

Regardless of its consequences, the automobile has played an enormous role in the lives of people throughout the world. It began as an enhancement to life but, subsequently, in many cases has 
encouraged a dependent and polluted society. Especially in industrialized societies, the use of automobiles has resulted in the dependency on petroleum, a fossil fuel that is finite and mostly imported from the Organization of Petroleum Exporting Countries (OPEC), which is primarily made up of Middle Eastern Countries. Today, the United States is importing over half of its oil from these relatively unstable countries that in turn could pose a national security threat (Transportation Research Board, 1998).

The increasing use of oil products has also increased air pollution in our cities. Air pollution is a major problem as pollutants such as Nitrogen Oxides, Carbon Monoxide and Hydrocarbons are released into the atmosphere with the most controversial pollutant being Carbon Dioxide $\left(\mathrm{CO}_{2}\right)$. $\mathrm{CO}_{2}$ is the main man-made pollutant produced that is causing the warming of the Earth's atmosphere. "Climate Change" is a consequence that can not be afforded, as some of its ultimate consequences include sea level rising, infrastructure damage, salt water intrusion, stronger storm systems and an increase in tropical diseases.

A valuable resource being placed in jeopardy by the automobile is land. The "urban flight" movement or "sprawl" began in the 1950s and 1960s when most of those who could afford to left the cities to live in a land of "suburbia" where everyone had their own space away from the ills of the inner city. However, there has been a backlash as people are finding themselves living in pedestrian-unfriendly, walled communities. The result has created monotone living quarters that lack individuality. Many people now live in places that have just as much, or in some cases more, congestion than where they were originally.

While the automobile has enabled people to travel from their suburban homes to the city to work, commutes have become longer and more congested. As a result of this mass movement, the 
normal day-to-day operation of our transportation system is becoming a concern to elected officials, planners, the business community and residents. These concerns relate to many different issues including congestion on local roads at all hours of the day and poor air quality due to vehicle emissions.

For years, the solution to rising levels of congestion was to build new roads and expand existing ones. This encouraged more growth to occur in areas of now perceived better accessibility, which ultimately resulted in much more congestion. Although road improvements will continue to be an important strategy for providing mobility, many communities no longer have the financial resources to build many new roads and, in any case, new road projects will most likely encounter strong public opposition. In addition, for those urban areas not in attainment with the federal clean air standards, federal law places substantial constraints on the type and magnitude of road expansion that can be undertaken (Offord, 1999). This creates a dilemma for transportation planners looking towards a future urban area filled with congested highways and unsatisfied motorists. When society cannot build its way out of traffic congestion, a solution must be found to better utilize the existing road system. In many parts of the United States, a new approach for providing transportation mobility that addresses many of these problems is being implemented through Transportation Demand Management (TDM) practices.

\section{The Study's Objectives}

The goal of this research project is to explore the concept of TDM by looking at its history and its implementation by Commuter Assistance Programs (CAP) in Florida (with a focus on the south Florida program). Independent evaluations of the south Florida program and case studies of 
individual companies adopting TDM initiatives will be discussed. This discussion has three specific objectives:

1. To use the South Florida CAP as a case study in order to determine whether TDM programs can be effective instruments for relieving traffic congestion and, therefore, obtaining social, environmental, and economic benefits.

2. To describe and, possibly, quantify said benefits in the case of the South Florida CAP.

3. To make recommendations on actions which can be taken in the future to strengthen CAPs and implement TDM initiatives more effectively. 


\section{Chapter 2}

\section{Transportation Demand Management}

\section{What is Transportation Demand Management?}

TDM is a combination of strategies or actions whose goal is to reduce traffic congestion during peak commuting times (usually $6 \mathrm{AM}-9 \mathrm{AM}$ and $4 \mathrm{PM}-7 \mathrm{PM}$ ). TDM strategies may include encouraging the use of commute mode alternatives such as public transit, carpooling, vanpooling, bicycling and walking. Other TDM alternatives that can be implemented by a company include alternative work hours or flextime, telecommuting, compressed workweeks, parking management, financial incentives, and education.

While mode alternatives directly affect the number of vehicles on the road, strategies such as alternative work hours and compressed workweeks influence when travel occurs during a day, or if it occurs at all on some days. In these cases, employees work a full 40-hour workweek in fewer days (most commonly in four days) with flexible work schedules. This allows employees to shift their work start and end times to less congested times of the day (Transportation Research Board, 1986). Another alternative, which influences where work occurs and how often a trip is made, is telecommuting. Telecommuting programs allow employees to work one or more days at home or at a satellite work center that is often closer to their homes, thus not requiring a long commute into the home office (Center for Urban Transportation Research, 1993).

For TDM alternatives to be effective, the application of TDM programs and the implementation of supporting strategies must occur in cooperation with the business community (Transportation Research Board, 1997). The employers must become the primary implementers of the TDM 
actions with the support and guidance of a CAP. With this assistance, businesses avoid the hidden costs associated with improper management of transportation programs. Incentives employers can utilize to encourage employees to adopt TDM initiatives include preferential parking for ridesharing, subsidies for transit riders, transportation allowances, parking management programs, on-site availability of transit schedules, periodic prize drawings for ridesharers, and Emergency Ride Home (ERH) programs.

Business leaders often do not realize how much money their company is spending on parking and simply write it off as a business expense. Reducing the number of parking spaces needed, they can lower employers' parking costs and add profit to their bottom line. In some cases an Employee Transportation Coordinator (ETC) is hired or a percentage of an employee's time is dedicated to implement desired TDM initiatives. From the employee's perspective, some view TDM initiatives such as ridesharing, telecommuting and flextime as a company-offered benefit, much like health care or paid vacation. This is true even if the employer is only managing the program and not subsidizing commute costs. Once educated about the benefits of such a program, most employees realize TDM initiatives will help them lower their commute costs, arrive to work less stressed and provide them with more reliable and dependable transportation.

Other benefits derived from a properly implemented TDM program are employee retention rates, traffic congestion reductions and air quality improvements. Finding good employees is always hard. If a business is not located where potential employees live, recruitment tasks can be more difficult. TDM programs, such as vanpools, ridesharing, shuttle buses and transit subsidies allow employers to recruit at distances farther than most workers are willing to drive. Although hiring employees from afar increases commute times and air emissions, if implemented with TDM 
programs, such as vanpooling and carpooling in high occupancy vehicle (HOV) lanes, air pollutant emissions can be minimized.

The development of the TDM program should consist of complementary actions. For example, a ridesharing program can become more effective if some form of preferential treatment is provided like HOV lane or preferential parking at the work site. To alleviate the fear of being trapped at work in case of an emergency an ERH program can be established to complement the rideshare or transit program. A truly effective TDM program must consider how TDM alternatives and strategies complement each other. With the right mix of TDM alternatives and strategies, a TDM program at individual employment sites can be very effective, reducing vehicle trips by as much as 30 to 40 percent (Transportation Research Board, 1986). Programs can be tailored to work-site conditions, market demographics and trip-making patterns. Information dissemination can be targeted to employees, thus adopting a corporate "culture" that reinforces the TDM message. Effective programs in the end employ a wide variety of TDM alternatives and strategies, each supporting the overall objective of trip reduction.

The best approach to implementation is to drive the process by information. There needs to be a good understanding of what the problem is and which markets, such as peak hour commuters, should be targeted for solving the problem. Decisions can then be made on what TDM alternatives and strategies need to be put in place. Because TDM strategies seek to change human behavior, they are often at first resisted by employees (Transportation Research Board, 1998). Successful designs of these programs call for the support from upper management. The key then to a successful program is an effective implementation strategy. The best TDM plan will go nowhere unless thought has been given to what steps should be taken and by whom. 
Success in putting together effective TDM programs lies in developing commitment and coordination within the organization.

TDM actions often require substantial changes in behavior. Such changes are notoriously hard to attain. Proper motivation is necessary to achieve the desired changes in behavioral patterns. A review of the history of TDM can reveal which actions are effective in achieving change and help explain why they occurred.

\section{A Historical Perspective}

"The term "TDM" didn't come into general usage until sometime during the 1970s. In the early 70s, this was generally covered under "transportation systems management" or TSM. As evaluations of TSM became more common, the focus shifted more towards the supply and the demand side of transportation systems. The demand side consideration led to the term "TDM." In southern California, the regional transportation plan probably referred to TDM for the first time in 1977 or slightly later" (Widby, 2000).

Understanding the TDM concept is essential, but it is also important to know when, where and why TDM emerged to appreciate its importance. However, no documented history of TDM has yet been published. Consequently, in this section, I will present a historical account of TDM based primarily on interviews with long-term practitioners. The story that emerges highlights TDM's evolution as a response to some of America's most memorable events in recent history showing that transportation management has deep roots in history. 
"One could argue that TDM began with the first pedestrian-only precincts in the middle age cities. Where do you draw the line? It depends on what you are trying to get at. In terms of ridesharing promotion, there was extensive promotion of carpooling as a part of gasoline rationing in World War II (WWII)" (Roach, 2000).

The first major event that spurred ridesharing was World War II. During this era there were significant efforts undertaken to promote carpooling in order to conserve rubber and gasoline. The American people took these conservation efforts very seriously as they felt a patriotic duty to help fight the war. Figure 1 illustrates the importance attached to ridesharing by war planners.
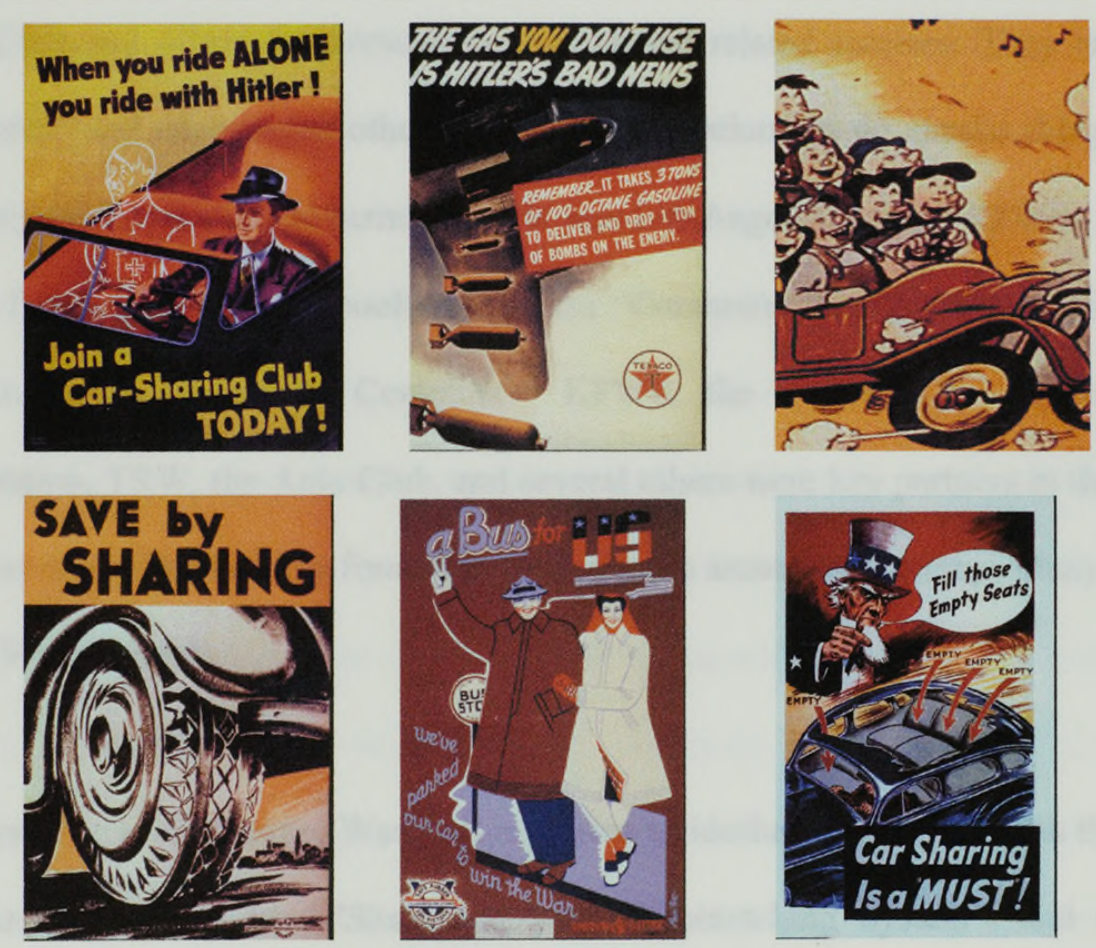

Figure 1: Six WWII Posters Promoting Ridesharing

Thirty years later another International crisis spurred ridesharing and the advent of high occupancy vehicle (HOV) lanes in the U.S. The 1973 Arab-Israeli War instigated this crisis. In an effort to pressure the U.S. and other Western nations to stop supporting Israel, the Arab members of the Organization of Petroleum Exporting Countries (OPEC) wielded petroleum as a 
weapon. From October 1973 to November 1974, the oil-producing Arab countries maintained an embargo on oil exports to Western nations friendly to Israel, causing gasoline shortages and higher oil prices. In the end, the embargo had a serious negative effect on the economy.

Once again, as a result of the embargo, ridesharing programs began sprouting up in the U.S. "TDM was an orphan child, it had no mother or father. But it had many adoptive parents" (Glazer, 2000). Glazer recalls that the WBZ Westinghouse Broadcasting radio station in Boston, Massachusetts, organized one of the earliest actions in 1972-3. They formed an alliance with the Auto Club and others to promote carpooling and related services. They called it "Commuter Computer" and encouraged other Westinghouse stations to do similar things in their markets. The only market it attained permanence in was Los Angeles through KFWB. That effort evolved to the first region-wide carpooling program "Commuter Transportation Services, Inc." (CTS), also known as Commuter Computer. KFWB, the City of Los Angeles, The Aerospace Corporation, TRW, the Auto Club, and several others were key partners in the founding of CTS. "Similar organizations were formed in several areas around the country. Many claim to have been first" (Widby, 2000).

In November 1973, Seattle, Washington started a ridesharing program with the idea to develop a ridematching system (the "Share and Save Ridematching System") and to manage priority carpool parking under I-5 in downtown Seattle. Widby states that they also promoted "vanpooling" which had been started by 3-M in St. Paul, Minn. in early 1973. The Seattle program was a response to a Clean Air initiative resulting from the region being out of compliance with EPA Clean Air regulations in 1973. 
As ridesharing programs continued to proliferate throughout the U.S., it became necessary to communicate the experiences gained. Two National conferences held within two years of each other provided the necessary forum for discussion of lessons learned and for the exchange of ideas among early TDM practitioners. First, in the late fall of 1974, Washington D.C. held a conference at the National Academy of Sciences on Constitution Avenue. "I remember Don Morin representing the Federal Highway Administration (FHWA) and pushing for the lanes on the Shirley Highway opening to carpools of 4 or more. He also talked about bus pools from Reston, Virginia. I remember hearing a presentation from Dr. Frank Davis about the activities they had started in Knoxville with Tennessee Valley Authority and other employers in Knoxville" (Roach, 2000). Then in 1975 Houston, Texas hosted the "Conference on Area-wide Carpooling" which was sponsored by the FHWA. "There was already a (modest) body of experience to discuss at that time, and over 60 people attended" (Glazer, 2000).

The establishment of professional organizations to facilitate the coordination of activities and the dissemination of knowledge was the next important step in the evolution of TDM programs in the U.S. The first such organization, the National Association of Vanpool Operators (NAVPO), was formed in the late 70 's. Soon after, in the early 80 's, the Association for Ridesharing Professionals (ARP) was formed. To better represent the alternative mode commuting public, NAVPO changed its name to the Association for Commuter Transportation (ACT) in 1983 and moved its headquarters from Tennessee to Washington, D.C. In a further development, ARP merged with ACT to create a unified voice for TDM professionals and programs nation-wide. As America's most respected organization for commuting professionals, ACT works hand-in-hand with business and government to make roads less crowded, make the air cleaner, and make commuting easier. ACT founded the TDM Institute in 1990, to conduct research and provide educational opportunities to the membership and the public. 
While energy (specifically petroleum) and other material shortages provided the impetus for the evolution of modern TDM programs, other developments secured continuing interest in such programs since the early 1980s. Urban sprawl and its attendant traffic congestion sparked interest in methods for providing incentives for carpooling and vanpooling such as high occupancy vehicle (HOV) lanes. Today, TDM continues to be a driving force for addressing traffic congestion by promoting alternative transportation choices we as a society should be able to accept!

This review of the history of TDM reveals that motivations of transportation planners have been the determining factor of the success of such programs to effect change in transportation behavior. Crises of the magnitude of WWII and the oil embargo were necessary to motivate people to change their driving behavior. Modern TDM programs face the challenge of effectively engaging the public in the absence of a widely perceived crisis. 


\section{Chapter 3}

\section{Commuter Assistance Programs}

\section{Defining a Commuter Assistance Program}

A CAP is an entity that utilizes TDM initiatives to make available alternative travel choices to employers and employees within a defined region. According to Bill Mustard, a former FDOT employee who worked on the creation of the Florida CAPs, in 1977 the "Transportation Control Plan " was written by FDOT for Florida, which created seven district rideshare programs. At that time there were seven non-attainment counties as per the Environmental Protection Agency's (EPA) one-hour minimum ozone requirement: Miami-Dade, Broward, Palm Beach, Hillsborough, Pinellas, Orange and Duval Counties. These counties were to begin a rideshare program to mitigate air quality in their respective areas. In 1979 a law was passed forbidding these counties to seek funding from State sources, therefore, they sought funding from the Federal level. Then in 1981 the "Ridesharing Law" was passed that abolished the 1979 Law. The FDOT then allotted $\$ 75,000$ to each of the seven counties to start their program. In 1989 the Center for Urban Transportation Research (CUTR) conducted a study for the FDOT, which found that regional programs would be more effective than individual jurisdictional programs (FDOT, 1988). This was the impetus for the first regional CAPs.

Currently, there are four regional CAPs in Florida. This study will look at the following three established programs: Commuter Services of North Florida (CSNF), Bay Area Commuters (BACS) and South Florida Commuter Services (SFCS). The fourth program, in Jacksonville, is still in the early developmental stages, thus, not suitable for evaluation purposes. The Florida Department of Transportation (FDOT) funds each of these CAPs. Because a different type of 
entity operates each CAP, they have been uniquely tailored to address the needs of their region. In addition, each CAP is located within a different FDOT district which dictates how much funding is made available each year depending on needs, population and other factors.

Although the specific objective of this research project is to evaluate the effectiveness of South Florida's CAP, investigation of the organization and operation of other Florida CAPs can provide useful information to this end. This is because evaluation of program effectiveness requires attention to not only whether or not a program attains its objectives, but also how well it performs relative to other comparable programs. Furthermore, analysis of the operation of the other Florida CAPs has the potential to provide examples and generate ideas for improvements for the South Florida CAP.

\section{Commuter Services of North Florida}

CSNF is based in Tallahassee. Program Manager, Pat Maurer, states "our commuter assistance program was launched in 1992 as the Capital City TMA. The organization is comprised of businesses, educational institutions, government, and community leaders dedicated to developing innovative solutions to their specific transportation needs." It is governed by a 15 -member board of Directors representing both public and private interests throughout the Big Bend region which consists of the following counties: Leon, Wakulla, Liberty, Taylor, Franklin, Calhoun, Gadsden, Madison, Jefferson, Jackson. The program is considered regional and the service area covers both urban and rural areas.

CSNF has instituted a number of programs and services to help commuters find more economical and environmentally friendly ways of getting to and from work. Many of these services are 
available directly to commuters such as computerized ridematching and the Guaranteed Ride Home (GRH) Program. The GRH Program is the primary incentive offered to carpoolers.

Work is also done with employers to help them identify and solve problems resulting from transportation barriers. "All members of the Tallahassee Area Chamber of Commerce receive a copy of our quarterly newsletter. Specific employers who have been identified as targets are initially contacted by phone and a site visit arranged to make a 'needs assessment"' (Maurer, 2000). The program also educates employers on commuter tax benefits, and has established a subsidized transit pass program for State of Florida employees. The annual "B-BOPP to Work" campaign features Transportation Fairs at major employer sites and a downtown festival with free breakfast and/or lunch, live music, and includes prize drawings and T-shirt giveaways. "B-BOPP generates a tremendous response from the general public; however, the GRH program is the major recruitment tool on a day to day basis" (Maurer, 2000).

Marketing tactics include using primarily print media such as brochures, newsletters and posters. Maurer explained that timely press releases (most recently, concerning rising gas prices) provide CSNF with television interview opportunities, minimizing the need to purchase advertising. To promote the B-BOPP campaign, newspaper and radio ads are used.

Because CSNF goals are regional in scope, it coordinates its activities with local governments within its service area to promote commute alternatives and encourage efficient use and expansion of the existing transportation system. CSNF personnel consist of two full-time staff, five marketing and support staff, and student assistants who are hired as needed. These individuals are responsible for conducting ongoing outreach activities, making presentations to 
local governments and promoting interest in alternative transportation programs. These activities ensure that proper attention is given to the interests of commuters in the Big Bend.

Currently, there are 2,584 applicants in the rideshare database, representing 399 employers. These applicants represent $0.7 \%$ of the total population of approximately 360,000 . CSNF's total budget is $\$ 250,000$ with $\$ 198,891$ for labor, $\$ 39,204$ for expenses, and $\$ 11,905$ for overhead (5\%). At this time there are no formal evaluations of the effectiveness of the program.

\section{Bay Area Commuter Services}

BACS is a private, non-profit organization, founded in 1991 to promote transportation alternatives to the commuting public in the rural and urban areas of Citrus, Hernando, Hillsborough, Pasco, and Pinellas counties. With the Tampa Bay area being ranked $22^{\text {nd }}$ in congestion in 1999 in the United States (U.S. Census Bureau, 1999), BACS' mission is to operate a regional CAP, and to actively lessen the demand on the roadway system through a program of support to private businesses, individuals, and public entities. BACS is located in the Westshore area of Tampa and offers a free service not only to the general public but also to local employers interested in implementing TDM initiatives at the work site.

BACS offers a confidential computerized match list database that is available to link individuals with other prospective ridesharers. The computer program considers such variables as worksite, home neighborhood and work hours. BACS then provides a match list of prospective rideshare partners, their work phone numbers and addresses. They also help with tips on forming a carpool or vanpool. To assist commuters in choosing an alternative mode of transportation, BACS' GRH program ensures that an alternative mode user will never be stranded at work. A commuter must 
carpool, vanpool, ride the bus, bicycle or walk to work at least two days a week to be eligible for a free (or low cost) taxi ride home or to an emergency destination. "The GRH program is the only free program we offer the public. This program grants the applicant up to 8 free taxi rides home per year in the event of unscheduled overtime, family emergency, illness, etc. The only stipulation is that the applicant is using some form of commute alternative at least 2 days per week" (Trosky, 2000). According to Trosky, the GRH program is an important benefit offered to the public to encourage ridesharing.

BACS is continuously trying to develop new marketing tools to increase commute alternative awareness. BACS' most successful tool has been the "Zipcode Analysis" map. After an initial meeting, the employer provides BACS with a database of employee zipcodes. Once the zipcode information is obtained, they are able to generate a Zipcode Analysis map based on the company location and the zipcodes of all of the employees. "Employer Outreach is a large part of what we do. We have a database of about 1,400 companies that are our main targets. Our marketing team does do some cold calling but more importantly contact is usually through letters and what we call "Employer Packets." These packets include marketing materials, brochures on all of our services (transportation issues associated with the relocation of a company, vanpooling, guaranteed ride home program and other commute alternatives), tax benefits and case studies of other companies who have successful commute alternative programs" (Trosky, 2000).

The Bay Area Vanpool Program was started in September of 1995 to accommodate larger groups of individuals wanting to ride together. Two transit agencies, HARTline and PSTA, sponsor the program with funding through the Florida Department of Transportation. Bay Area Vanpool works in conjunction with BACS to help organize vanpools throughout the Tampa Bay area. "Our vanpool program, although still suffering growing pains, is also a very popular program, 
especially by those who are currently in the program. The majority of our vans have been on the road for several years" (Trosky, 2000).

There are 2,759 active applicants representing 140 companies in their regional rideshare database, which represent $0.1 \%$ of the total population of approximately 2.4 million. BACS' annual budget is $\$ 550,000$, which includes: $\$ 390,000$ for labor, and $\$ 160,000$ for marketing and miscellaneous expenses. The staff consists of eleven full-time employees and two full-time, grant-funded staff. Currently, there are no formal evaluations of the program to ensure its effectiveness.

\section{South Florida Commuter Services}

SFCS was founded in 1989 and was designed to service Miami-Dade, Broward and Palm Beach counties. Currently, the program is run by a private consulting firm, URS Corporation, and goes "out to bid" every two years. SFCS' former Project Director, Thomas Cerny, explained that this program has been designed to provide free support and leadership to businesses in the community to effect change in transportation behavior. The program's mission is to improve traffic conditions by reducing South Florida's dependency on the Single Occupant Vehicle (SOV).

SFCS promotes a wide variety of commute options such as carpooling, vanpooling, transit, workhour management, telecommuting and other non-motorized alternatives to both employers and the general public. SFCS maintains a regional rideshare database that matches commuters, who are interested in ridesharing, live near one another, work near one another and commute during the same times. Once in the database, applicants receive a match letter every quarter and a follow-up courtesy phone call to answer any questions they might have about the program. 
The Emergency Ride Home (ERH) program is offered to those individuals who work in the triCounty area. The program ensures that those commuters using an alternative mode of transportation (transit, carpool, vanpool, biking, walking, etc.) at least 3 days a week will lessen the likelihood of being "trapped" at work without a ride. In case of an emergency or if asked to work unscheduled overtime, applicants are able to use up to six vouchers a year to cover the cost of a taxi ride home or wherever the emergency dictates. There are no restrictions placed on the dollar amount to be spent on a single trip. Restrictions are placed on the length of the trip, which is not to exceed 50-miles outside the tri-county borders.

SFCS operates a 1-800 call center that answers questions regarding all types of commuting options. Operators are available from $8 \mathrm{AM}$ to $5 \mathrm{PM}$ and have the ability to transfer the caller to any transit agency within the tri-county as well as to the Transportation Management Associations or Organizations (TMAs/TMOs) in the area for detailed information. After 5 PM the automated system can transfer callers to the appropriate agency and handle ERH callers from all three counties.

To promote SFCS' programs at their facility, a company can request either a staff meeting presentation or a "SFCS Day" at their facility to sign up applicants. SFCS representatives will explain the programs that are offered and answer any questions that are posed. Employers holding an event will receive a follow-up report detailing the commute patterns of their employees and how the company and the employees will benefit from ridesharing. In addition, recommendations and next steps will be discussed on ways to increase employee participation rates and on adopting TDM initiatives. 
While SFCS does not have a large budget for marketing, it is still considered a major part of the program's success. Marketing efforts to the general public and employers include, but are not limited to, 30-second radio ads, peak hour traffic report sponsorships, billboards and quarterly newsletters. Linda Flynn, SFCS' Regional Marketing Coordinator, explains "even with such a limited budget, our marketing approach is getting our point across by being creative and efficient in our decisions!"

SFCS works closely with the South Florida Vanpool Program (SFVP). FDOT and the Miami-Dade County Metropolitan Planning Organization fund the program jointly. If an individual lives and/or works in Miami-Dade County and has a group of 7-15 people, SFVP will lease a van for a monthly fee based on monthly mileage and van size. The monthly fee includes lease of the van, all maintenance, insurance and the ERH program. Monthly fees average $\$ 65$ per person, with the primary driver riding for free. "This offer is perfect for South Florida commuters who not only want to save a lot of money, but who want to get to work without stressful traffic hassles," explained Alice Lee-Cook of the South Florida Vanpool program.

Finally, a new concept, the Transportation Management Initiative (TMI), has been introduced by SFCS in Miami-Dade County because of the County's population density and increasing traffic congestion. TMIs are joint public/private programs established to develop and implement solutions to local traffic congestion and/or commuting problems. TMIs seek to accomplish these solutions through the promotion of TDM initiatives. TMIs are formed through the cooperative effort of the private sector, local government, regional government and state government and serve a specified geographic area. 
TMIs differ from TMAs and TMOs in that they are not stand-alone agencies. Unlike a TMA or TMO, which are independent non-profit organizations guided by their respective Board of Directors, hired staff, bylaws and articles of incorporation, TMIs are simply "branch offices" of the Regional Commuter Assistance Program (CAP). The TMIs' staff reports to the Regional CAP Director and is supported by the marketing, planning and administrative staff of the regional program. "This allows personnel assigned to the TMI to concentrate on program implementation without the normally burdensome administrative tasks encountered by TMA/TMO Directors (especially in the early stages of TMA formation) (Cerny, 2000)." They also facilitate alignment of local and regional TDM goals while still providing specific attention to specialized local needs. To ensure local needs are being met satisfactorily, a TMI Advisory Committee is established. Made up of local community leaders and the TMIs' funding agencies, this group helps set goals and monitors progress.

TMIs are funded through mixes of local (public and private), regional, state and federal funds. Cerny explains that, generally, Federal and State governmental funding sources will expect some contribution/financial commitment from the locality seeking to start a TMI. This contribution/commitment can be in matching funds, in-kind contributions or a combination of both. Typical in-kind contributions include the provision of office space, office equipment, printing, phone systems, secretarial assistance, legal support and accounting services.

Currently, there are two TMIs servicing specific areas within Miami-Dade County. Airport West TMI was established in 1998, while the Downtown Miami TMI was established in 1999. Geographical boundaries for the AWTMI as seen in Figure 2 are Flagler Street to the South, Florida's Turnpike to the West, NW $58^{\text {th }}$ Street to the North, and Okeechobee Road and LeJeune Road to the East. DMTMI serves the Central Business District (CBD) area bordered by NE $24^{\text {th }}$ 
Street to the North, SE $15^{\text {th }}$ Road to the south, I-95, Miami Avenue, the Miami River and NE $2^{\text {nd }}$ Avenue to the west, and Biscayne Bay to the east, including Watson Island, Bayside and Brickell Key as seen in Figure 3. The DMTMI will also assist companies that border the boundary area.

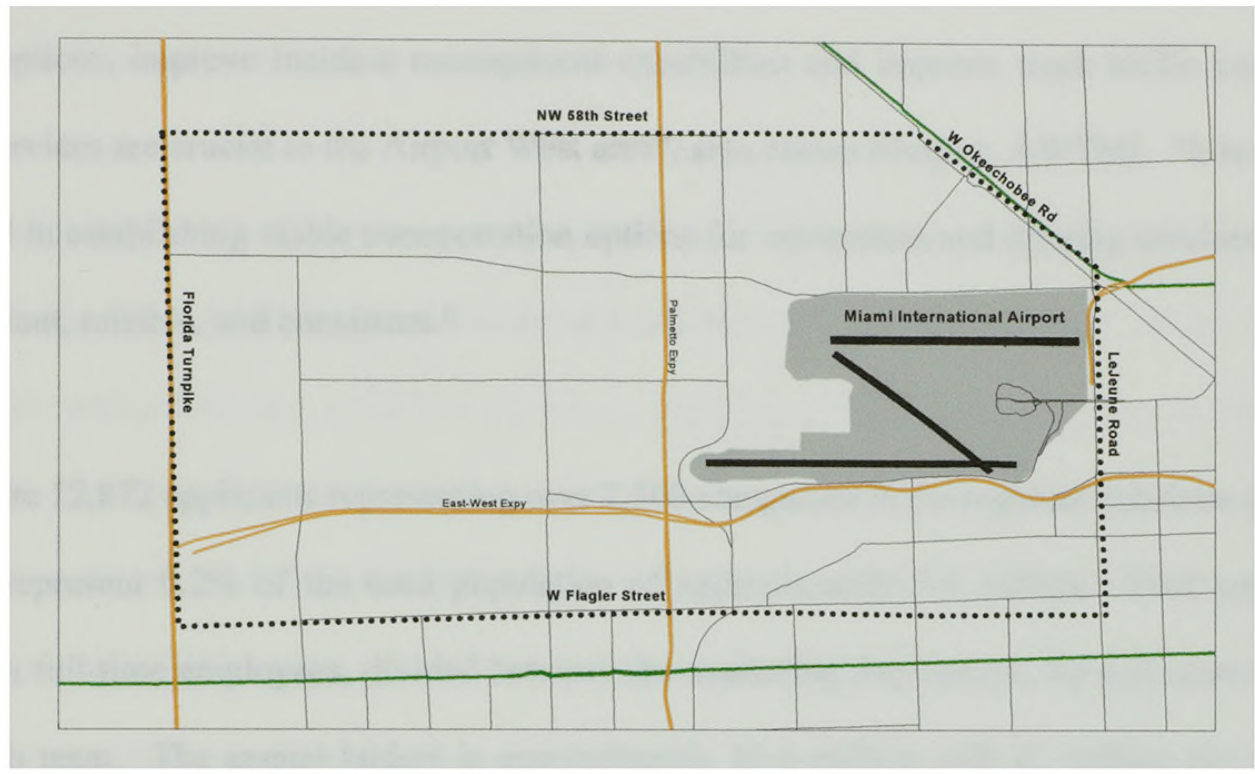

Figure 2: AWTMI Boundary Map

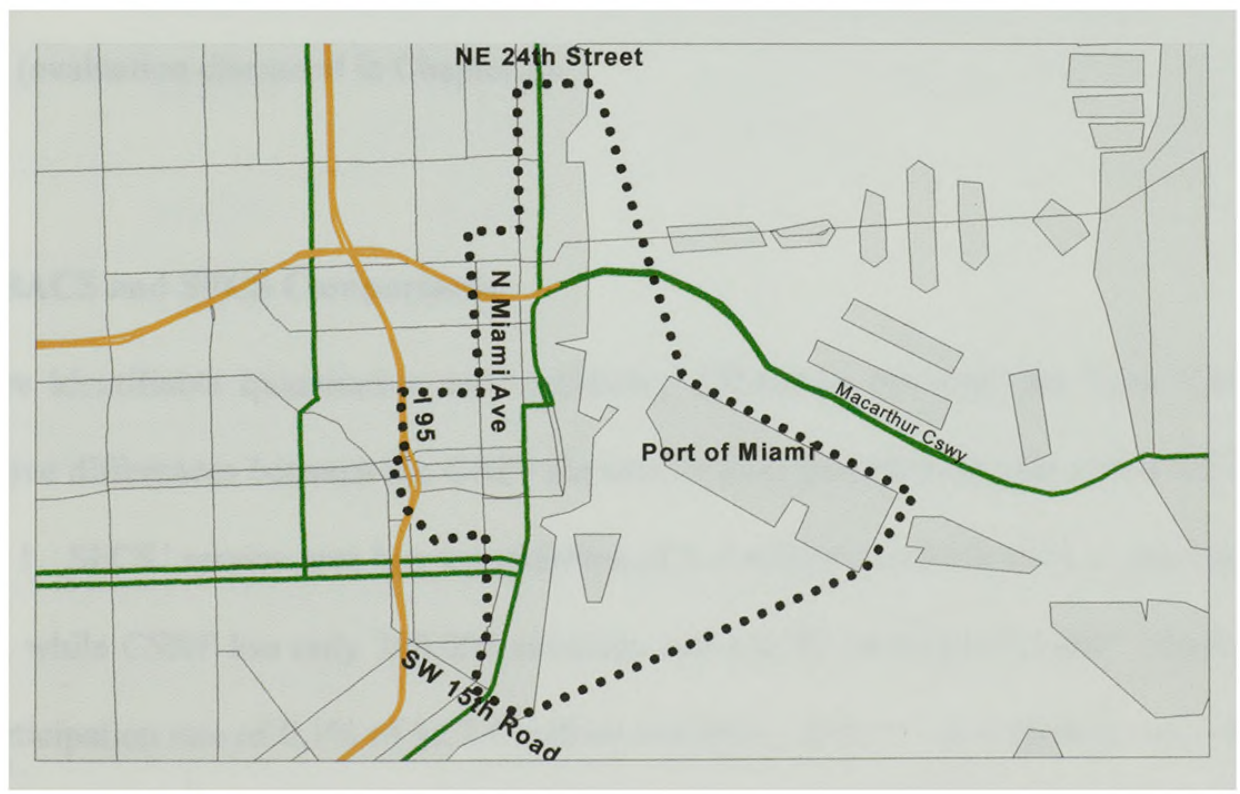

Figure 3: DMTMI Boundary Map 
The purpose of both TMIs is to identify goals and projects for their designated areas, describe the process that will be used to achieve them, and establish how progress will be measured. Their goals are to improve mass transit services, advocate transportation improvements, implement TDM options, improve incident management capabilities and improve truck traffic conditions. "Our services are crucial to the Airport West area", says James Murphy, AWTMI. "It is one step forward in establishing viable transportation options for commuters and offering services that are convenient, reliable, and consistent."

There are 12,872 applicants representing over 2,500 companies in the regional rideshare database, which represent $0.2 \%$ of the total population of approximately 5.4 million. Staff consists of fourteen full-time employees, divided between the marketing department, the call center and the outreach team. The annual budget is approximately $\$ 1.6$ million with $\$ 1$ million for staff and optional services and $\$ 600,000$ for the ERH program and marketing efforts. SFCS has been independently evaluated on a yearly basis since 1997 to determine the effectiveness of the program (evaluation discussed in Chapter 3).

\section{CSNF, BACS and SFCS Comparisons}

There are identifiable quantitative and qualitative differences between the three CAPs. The quantitative differences between the CAPs are seen in their participation rate and in their budgets in Table 1. SFCS' service area has a population of 5.4 million residents with a participation rate of $0.2 \%$, while CSNF has only 360,000 residents and a $0.7 \%$ participation rate. Finally, BACS has a participation rate of $0.1 \%$ of its 2.4 million residents. BACS' participation rate is reflective of a low marketing budget and CSNF's rate is reflective of program longevity and a lower 
population. Before the appointment of the new consulting firm in 1996, SFCS had less than 100 valid applicants in the database. Since that time, they have added approximately 20,000 applicants into the database at an average rate of 5,000 per year for four years (updates to applicants' information often purge a number of individuals allowing those who are interested and that have correct information to remain in the database).

Budgets are important factors in a program's success. CSNF's total budget is $\$ 250,000$ with $\$ 198,891$ for labor, $\$ 39,204$ for expenses, and $\$ 11,905$ for overhead. BACS' annual budget is $\$ 550,000$, which includes: $\$ 390,000$ for labor, and $\$ 160,000$ for marketing and miscellaneous expenses. The annual budget for SFCS is approximately $\$ 1.6$ million with $\$ 1$ million for staff and optional services and $\$ 600,000$ for the marketing efforts. All budgets take into account their respective GRH/ERH program. The following table shows the per capita costs for their respective populations and applicants.

\begin{tabular}{||l|c|c|c|c|c||}
\hline \multicolumn{7}{|c|}{ FLORIDA CAPS' POPULATION AND APPLICANTS PER CAPITA } \\
\hline AGENCY & BUDGET & $\begin{array}{c}\text { TOTAL } \\
\text { POPULATION }\end{array}$ & $\begin{array}{c}\text { \$ PER } \\
\text { RESIDENT }\end{array}$ & APPLICANTS & $\begin{array}{c}\text { \$ PER } \\
\text { APPLICANT }\end{array}$ \\
\hline CSNF & $\$ 250,000$ & 360,000 & $\$ 0.69$ & 2,584 & $\$ 96.75$ \\
\hline BACS & $\$ 550,000$ & 2.4 Million & $\$ 0.23$ & 2,759 & $\$ 199.34$ \\
\hline SFCS & $\$ 1.6$ Million & 5.4 Million & $\$ 0.30$ & 12,872 & $\$ 124.30$ \\
\hline
\end{tabular}

Table 1: Florida CAPs' Population and Applicant Per Capita

SFCS has the largest budget because two FDOT Districts contribute and the population is very large. CSFN spends more per capita for its total population whereas it spends the least on its applicants. BACS has the opposite situation with SFCS being in the middle of the two agencies. 
The qualitative differences between the CAPs are indicated by the entities that operate them and the evaluation process or lack thereof. BACS is operated by a non-profit organization, SFCS by a private consulting firm, and CSNF is run as a TMA with a Board of Directors. As far as evaluating is concerned, SFCS is the only entity that actually requests an evaluation of their services. This is done mainly due to the program going out to bid on contract every two years thus creating a competitive and innovative thinking atmosphere. Staff must continue initiating new, successful programs to ensure the client's satisfaction. The other two entities do not have this pressure, thus being able to maintain the status quo should they choose.

What the three CAPs have in common is the use of the BACSCAP computer program utilized for ride matching and a form of ERH/GRH program. The BACSCAP computer program was originally developed by BACS and then turned over to Florida State University's (FSU) Marketing Institute. There the development of the program is funded by FDOT to meet the needs of the Florida CAPs. The software is then made available to the CAPs and each of them works in conjunction with FSU to tailor it to their own needs. Another parallel program is the ERH or GRH program. The rules are different at each CAP, but the main motive is to alleviate the fear of being trapped at work in case of an emergency.

Each CAP has its own focus and strengths. CSNF has a lot of support from the community because the Board Members represent different entities throughout the region. They focus heavily on educating their audience and hosting the annual B-BOPP to work event. BACS focuses on their GRH program and finding individuals a carpool partner through "Zipcode Analysis" maps. SFCS mirrors BACS' initiatives, but takes employer outreach further by presenting a full report to employers after an event has taken place. In addition, TMIs have been established to perform dedicated employer outreach to specific areas. 
The success of the CAPs can be determined by the participation rate in each region. Taking the data "Total Population" and "Applicants" from Table 1, CSNF has a participation rate of .7\% with BACS and SFCS having rates of $.5 \%$ and $.2 \%$, respectively. This shows that the CSNF has the highest applicant participation rate over the two other programs making it the most successful in signing up applicants into the program.

Although each CAP has its strengths, aggressive marketing is the key to a successful program. Marketing a concept that promotes a behavioral change such as commuting habits can be an arduous task. Therefore, public education is an essential part of the whole scheme. This and other recommendations to improve the success of the Florida CAPs will be discussed in chapter five. 


\section{Chapter 4}

\section{SFCS Independent Evaluations}

\section{Annual Evaluations}

To determine the effectiveness of the SFCS program, the Center for Urban Transportation Research (CUTR) has conducted an annual evaluation since 1997. These evaluations allow for determination as to what the strengths and weaknesses have been in the last four years and, in addition, which areas for future growth should be attended to by setting measurable goals in future years. CUTR performed surveys of the general public (GP), local businesses (LB) and SFCS' applicants (AP). Table 2 presents an overview of the survey methods and response rates.

\begin{tabular}{||c|c|c|c|c||}
\hline \multicolumn{5}{|c|}{ SURVEY METHODOLOGY $^{*}$} \\
\hline Year & Group & Method of Contact & Number Contacted & Response Rate \\
\hline \multirow{2}{*}{1997} & GP & Telephone & 300 & $52.5 \%$ \\
& LB & Mailed Survey & 1,190 & $17 \%$ \\
& AP & Telephone & $84 \%$ \\
\hline \multirow{2}{*}{1998} & GP & Telephone & 165 & $49.9 \%$ \\
& LB & Mailed Survey & 900 & $10 \%$ \\
& AP & Telephone & 1,500 & $82 \%$ \\
\hline \multirow{3}{*}{1999} & GP & Telephone & 1,066 & $40.6 \%$ \\
& LB & Mailed Survey & 750 & $20 \%$ \\
& AP & Telephone & $78 \%$ \\
\hline \multirow{3}{*}{2000} & GP & Telephone & 3,652 & $76 \%$ \\
& LB & Mailed Survey & 750 & $19 \%$ \\
& AP & Telephone & 800 & $81 \%$ \\
\hline
\end{tabular}

Table 2: Survey Methodology

*Data from CUTR Surveys 1997, 1998, 1999 and 2000 
For the purposes of this study, data from several CUTR reports have been combined to facilitate the analysis of possible trends. SFCS' staff was responsible for assisting in the evaluation by providing information such as number of active individuals in the rideshare database, number of individuals requesting assistance by either calling the 1-800 number or filling out an application, number of vans in service, number of employers requesting assistance, etc. Once the surveys were completed, CUTR determined the mode shift percentage and the vehicle miles traveled (VMT) reduced per commuter for the applicant that SFCS had influenced. Once the VMT was established, the number of vehicle trips eliminated, vehicle miles eliminated, parking spots saved and most importantly, commuter costs saved were calculated. Each year's VMT figures are shown in Table 3.

\begin{tabular}{|c|c|c||}
\hline \multicolumn{3}{|c|}{ VMT FIGURES PER APPLICANT* } \\
\hline & Mean Trips Reduced & Mean Miles Reduced \\
\hline 1997 & 46.6 & 671.3 \\
\hline 1998 & 77.1 & $1,790.8$ \\
\hline 1999 & 66.8 & 1,518 \\
\hline 2000 & 124.0 & 2,386 \\
\hline
\end{tabular}

Table 3: VMT Figures per Applicant

*Data from CUTR Surveys 1997, 1998, 1999 and 2000

For purposes of simplification, CUTR's and SFCS's information has been arranged into Tables 4 through 9: Rideshare Database and Call Center; Marketing and Public Outreach; Carpool and Vanpool; ERH Program; VMT Impacts; and TDM Initiatives. These tables will be used to compare specific "performance measures" for evaluation years $1997-2000$. 


\section{Rideshare Database and Call Center}

As seen in Table 4, the total number of applicants in the rideshare database has increased since 1997 as a result of marketing and outreach activities. The largest increase occurred between 1997 and 1998 from 753 to 6,017 applicants. This in part was due to a change in consulting firms in 1996 when the new consultant made it a priority to increase the awareness of the program among the general public.

\begin{tabular}{|c|c|c|c|c|c|}
\hline \multicolumn{6}{|c|}{ RIDESHARE DATABASE AND CALL CENTER RESULTS } \\
\hline Performance Measure & 1997 & 1998 & 1999 & 2000 & $\begin{array}{l}\text { How } \\
\text { Measured }\end{array}$ \\
\hline $\begin{array}{l}\text { Number Applicants in } \\
\text { the Database }\end{array}$ & 753 & 6,017 & 8,319 & 9,208 & $\begin{array}{l}\text { Collected by } \\
\text { SFCS }^{\mathrm{a}}\end{array}$ \\
\hline $\begin{array}{l}\text { Number of Calls } \\
\text { Requesting Assistance }\end{array}$ & 1,238 & 9,609 & 14,341 & 20,595 & $\begin{array}{l}\text { Collected by } \\
\text { SFCS }^{\mathrm{a}}\end{array}$ \\
\hline $\begin{array}{l}\text { Number of Customer } \\
\text { Calls into the } 1-800 \\
\text { Number to Receive } \\
\text { Rideshare Information }\end{array}$ & 1,238 & 2,912 & 8,485 & 15,668 & $\begin{array}{l}\text { Collected by } \\
\text { SFCS }^{\mathbf{a}}\end{array}$ \\
\hline $\begin{array}{l}\text { Percentage of applicants } \\
\text { who would recommend } \\
\text { SFCS }\end{array}$ & $45 \%$ & $42 \%$ & $50 \%$ & $47 \%$ & AP Surveys \\
\hline
\end{tabular}

Table 4: Rideshare Database and Call Center Data

a Data calculated by SFCS' staff $1997,1998,1999$ and 2000

${ }^{\mathrm{b}}$ Data from CUTR Surveys 1997, 1998, 1999 and 2000

In addition, the number of commuters requesting assistance by either filling out an application or calling into the 1-800 number has steadily risen as a result of marketing efforts and public outreach. The percentage of applicants has fluctuated within the 40-percentile range over the four-year period. However, the percentage of applicants who would recommend the SFCS has remained at or below $50 \%$. These low percentages show that half of all applicants in the SFCS program are not satisfied. This could be due to the fact that only $45 \%$ to $60 \%$ of all applicants 
receive a letter with potential carpool matches (see Table 6). Because the main goal of the program is to find a carpool partner, the individuals who have not found a carpool partner may well be unsatisfied with the program. This would explain the relatively low percentage of applicants willing to recommend the SFCS program.

\section{General Public Marketing and Outreach}

Media relations include press releases (PR), public service announcements (PSAs), newspaper articles, news stories, and magazine articles. Special events include, but are not limited to, "SFCS Days", "Commuter Fairs", special events with radio stations and "Park and Ride Lot" promotions.

In Table 5, PRs are specified to determine the amount of free press generated from these writeups. Calculations are based on the cost of an ad space and/or airtime times an industry average of 5 (Flynn, 2000). They have proved to be fruitful with one press release (PR) in 1997 generating $\$ 6,935.50$ to eighteen PRs in 1999 generating $\$ 626,551$ of free press equaling a $98 \%$ increase in just two years.

It can also be seen in Table 5 that years 1997 and 1999 focused on media relations, whereas 1998 and 2000 focused on special events employer outreach tactics. This is seen where the percentage trying an alternative mode based on advertising dropped in both 1998 and 2000 and had an opposite effect in years 1997 and 1999. This is also evident in the number of special events rising sharply in both 1998 and 2000. 


\begin{tabular}{|c|c|c|c|c|c|}
\hline \multicolumn{6}{|c|}{ GENERAL PUBLIC MARKETING AND OUTREACH RESULTS } \\
\hline $\begin{array}{l}\text { Performance } \\
\text { Measure }\end{array}$ & 1997 & 1998 & 1999 & 2000 & $\begin{array}{l}\text { How } \\
\text { Measured }\end{array}$ \\
\hline $\begin{array}{l}\text { Press Releases } \\
\text { (PR) }\end{array}$ & $\begin{array}{l}1 \text { PR Activity } \\
(\$ 6,935.50)\end{array}$ & $\begin{array}{c}5 \text { PRs } \\
(\$ 228,009)\end{array}$ & $\begin{array}{c}18 \text { PRs } \\
(\$ 626,551)\end{array}$ & $\begin{array}{c}16 \text { PRs } \\
(\$ 606,635)\end{array}$ & $\begin{array}{l}\text { Collected by } \\
\text { SFCS }^{\mathrm{a}}\end{array}$ \\
\hline $\begin{array}{l}\text { Percent aware of } \\
\text { promotional } \\
\text { materials }\end{array}$ & $38 \%$ & $26 \%$ & $33 \%$ & $46 \%$ & GP Surveys ${ }^{b}$ \\
\hline $\begin{array}{l}\text { Percentage of GP } \\
\text { trying an } \\
\text { alternate mode } \\
\text { based on } \\
\text { advertising }\end{array}$ & $2.3 \%$ & $1.4 \%$ & $2.7 \%$ & $2.3 \%$ & GP Surveys ${ }^{b}$ \\
\hline $\begin{array}{l}\text { Employer } \\
\text { Contacts via } \\
\text { Letter or Phone } \\
\text { Call }\end{array}$ & 31 & 25,753 & 39,055 & 62,069 & $\begin{array}{l}\text { Collected by } \\
\text { SFCS }^{\mathrm{a}}\end{array}$ \\
\hline Special Events & 20 & 80 & 95 & 227 & $\begin{array}{l}\text { Collected by } \\
\text { SFCS }^{\mathrm{a}}\end{array}$ \\
\hline
\end{tabular}

Table 5: General Public Marketing and Outreach Data

a Data calculated by SFCS' staff 1997, 1998, 1999 and 2000

${ }^{b}$ Data from CUTR Surveys 1997, 1998, 1999 and 2000

\section{Carpools and Vanpools}

The percentage of the applicants trying an alternative mode is related to the percentage of applicants receiving carpool matching information as well as the search radius used to locate potential carpool matches (see Table 6). In 1997, 60\% of the database received match lists with only $22 \%$ trying an alternative mode. It was determined that the search radius was too large (generating potential matches who lived and worked too far apart) so it was shortened in 1998 (see Table 11, Chapter 5). This resulted in fewer individuals receiving match lists. However, the percentage of applicants trying an alternative mode rose to $26 \%$. The two indicators dropped and 
rose together in 1999 and 2000 respectively. The decline in 1999 was a result of a major cleansing of the database. Cleansing usually means the deletion of members as they change residence or work location.

The number of commuters switching modes is the number of people that actually use the carpool match lists to change from their single occupant vehicle (SOV) mode to carpooling, vanpooling, transit, telecommuting, walking or bicycling. This increased from 1997 to 1998 , decreased from 1998 to 1999 and made a jump in 2000 to $20.4 \%$. This fluctuation could be related to the percentage of match lists generated and their usefulness to applicants. In addition, the duration of existing carpools has steadily increased from 1.53 years in 1997 to 2.71 years in 2000 .

Characteristics of alternative mode users were extrapolated from applicants in 2000. Information gathered from the 2000 CUTR report states that an alternative mode user is most likely to be married, without children, having a Bachelors degree, between the age of 45-54, and with an annual income of over $\$ 70,000.00$. The next highest level of alternative mode users consists of single persons without children, who attended some college, who are between the ages of 35-44 and have annual incomes of $\$ 20,000$ to $\$ 29,0000$. The group less likely to choose an alternative mode of transportation is divorced with no children, without a high school degree, between the ages of $18-24$, making less than $\$ 10,000$.

Finally, the number of vans in service was at 4 in 1999 and increased to 14 in 2000 . In the beginning, the program had been a "hard sell" in south Florida, thus, education efforts were stepped up to familiarize commuters with the concept of vanpooling. These efforts were successful, and vanpooling is increasingly becoming an important alternative transportation 
mode. The ERH program, as well, has had an effect in the increase of alternative transport mode users in general, and vanpool users specifically.

\begin{tabular}{|l|c|c|c|c|l||}
\hline \multicolumn{5}{|c||}{ CARPOOLING AND VANPOOLING AMONG APPLICANTS } \\
\hline $\begin{array}{l}\text { Performance } \\
\text { Measure }\end{array}$ & 1997 & 1998 & 1999 & 2000 & $\begin{array}{l}\text { How } \\
\text { Measured }\end{array}$ \\
\hline $\begin{array}{l}\text { Percentage of } \\
\text { database receiving } \\
\text { matching info }\end{array}$ & $60 \%$ & $57 \%$ & $46 \%$ & $52 \%$ & $\begin{array}{l}\text { AP } \\
\text { Surveys }\end{array}$ \\
\hline $\begin{array}{l}\text { Percentage of } \\
\text { database trying } \\
\text { alternative mode } \\
\text { based on match } \\
\text { lists }\end{array}$ & $22 \%$ & $26 \%$ & $23.4 \%$ & $36.8 \%$ & $\begin{array}{l}\text { AP } \\
\text { Surveys }\end{array}$ \\
\hline $\begin{array}{l}\text { Percentage of } \\
\text { commuters } \\
\text { switching modes }\end{array}$ & $7.9 \%$ & $11.0 \%$ & $10.2 \%$ & $20.4 \%$ & $\begin{array}{l}\text { AP } \\
\text { Surveys }\end{array}$ \\
\hline $\begin{array}{l}\text { Duration of } \\
\text { existing carpools }\end{array}$ & 1.53 years & 2.24 years & 2.67 years & 2.71 years & $\begin{array}{l}\text { AP } \\
\text { Surveys }\end{array}$ \\
\hline $\begin{array}{l}\text { Number of vans } \\
\text { in service }\end{array}$ & 0 & 4 & 4 & 14 & $\begin{array}{l}\text { Collected } \\
\text { by SFCS }^{\mathrm{a}}\end{array}$ \\
\hline
\end{tabular}

Table 6: Carpooling and Vanpooling among Applicants Data

${ }^{a}$ Data calculated by SFCS' staff 1997, 1998, 1999 and 2000

${ }^{b}$ Data from CUTR Surveys 1997, 1998, 1999 and 2000

\section{ERH Program}

The ERH program was initiated in 1998, therefore, there are no calculations for 1997 . Table 7 shows the percentage of applicants provided with ERH information increased as the size of the database increased. This information dissemination to applicants, along with marketing efforts to the general public has impacted the number of applicants in the ERH program. This has been a successful program for SFCS as participation has increased continually from 1998 to 2000. 
Success can also be quantified by the number of ERH rides provided which increased six-fold from 1998 to 1999 and then doubled in 2000 to 675.

\begin{tabular}{||l|c|c|c|c|l||}
\hline \multicolumn{7}{|c||}{ ERH PROGRAM RESULTS } \\
\hline $\begin{array}{l}\text { Performance } \\
\text { Measure }\end{array}$ & 1997 & 1998 & 1999 & 2000 & $\begin{array}{l}\text { How } \\
\text { Measured }\end{array}$ \\
\hline $\begin{array}{l}\text { Percentage of } \\
\text { database } \\
\text { provided with } \\
\text { ERH info }\end{array}$ & 0 & $62 \%$ & $76 \%$ & $80 \%$ & AP Surveys \\
\hline $\begin{array}{l}\text { Number of } \\
\text { applicants in the } \\
\text { ERH program }\end{array}$ & 0 & 765 & 2,527 & 4,029 & $\begin{array}{l}\text { Collected by } \\
\text { SFCS }\end{array}$ \\
\hline $\begin{array}{l}\text { Number of ERH } \\
\text { rides provided }\end{array}$ & 0 & 49 & 295 & 675 & $\begin{array}{l}\text { Collected by } \\
\text { SFCS }^{\mathrm{a}}\end{array}$ \\
\hline
\end{tabular}

Table 7: ERH Program Data

a Data calculated by SFCS' staff 1997, 1998, 1999 and 2000

${ }^{\mathrm{b}}$ Data from CUTR Surveys 1997, 1998, 1999 and 2000

\section{VMT Impacts}

The number of vehicle trips eliminated, vehicle miles eliminated, parking spots saved, commuter costs saved and gallons of gasoline saved have all increased as the database expanded (see Table 8). Finally, air emissions of Carbon Monoxide (CO), Hydrocarbons (HC), Nitrogen Oxide (NOx) and Carbon Dioxide $\left(\mathrm{CO}_{2}\right)$ have been reduced. Each measure was calculated as follows (the respective year's figures must be plugged into the formula):

\section{Number of Vehicle Trips Eliminated:}

This performance measure is calculated by taking the total active applicants for each year multiplied by CUTR's number of Mean Trips Reduced (Table 3). 


\begin{tabular}{|c|c|c|c|c|}
\hline \multicolumn{5}{|c|}{ VMT RESULTS } \\
\hline Performance Measure & 1997 & 1998 & 1999 & 2000 \\
\hline $\begin{array}{l}\text { Number of vehicle trips } \\
\text { eliminated }\end{array}$ & 35,992 & 323,288 & 445,859 & $1,022,132$ \\
\hline Vehicle miles eliminated & 518,495 & $7,509,003$ & $10,127,684$ & $19,667,798$ \\
\hline Parking spots saved & 73 & 660 & 910 & 2,086 \\
\hline Commuter costs saved & $\begin{array}{l}\$ 0.29 / \text { mile } \\
\$ 150,363\end{array}$ & $\begin{array}{l}\$ 0.29 / \text { mile } \\
\$ 2,177,000\end{array}$ & $\begin{array}{l}\$ 0.29 / \text { mile } \\
\$ 2,937,028\end{array}$ & $\begin{array}{l}\$ 0.29 / \text { mile } \\
\$ 5,703,661\end{array}$ \\
\hline Gallons of gasoline saved & 20,740 & 300,000 & 425,000 & 786,712 \\
\hline $\begin{array}{l}\text { Pounds of carbon } \\
\text { monoxide reduced }\end{array}$ & 32,288 & 688,286 & 806,649 & $1,403,388$ \\
\hline $\begin{array}{l}\text { Pounds of hydrocarbons } \\
\text { reduced }\end{array}$ & 4,119 & 87,815 & 102,917 & 179,053 \\
\hline $\begin{array}{l}\text { Pounds of nitrogen oxide } \\
\text { reduced }\end{array}$ & 2,115 & 45,094 & 52,849 & 91,946 \\
\hline $\begin{array}{l}\text { Pounds of carbon dioxide } \\
\text { reduced }\end{array}$ & 606,586 & $12,930,292$ & $15,153,890$ & $26,364,345$ \\
\hline
\end{tabular}

Table 8: VMT Impact Data

\section{Vehicle Miles Eliminated:}

This performance measure is calculated by taking the total active applicants for each year multiplied by CUTR's number of Mean Miles Reduced (Table 3).

\section{Parking Spots Saved:}

This performance measure is calculated by taking the number of vehicle trips reduced and dividing by 2 trips per day divide by 245 working days per year. 


\section{Commuter Costs Saved:}

This performance measure is calculated by multiplying vehicle miles eliminated by the average cost per mile of $\$ .29$ (this figure is taken from the federal government and State of Florida and is elevated due to the depreciation value being considered).

\section{Gasoline Saved:}

This performance measure is calculated by multiplying vehicle miles eliminated by the average 20-MPG figure from EPA (CUTR, 1999).

Neither CUTR, nor SFCS calculate the program's environmental impacts. Some environmental benefits (specifically, the reduction of air pollutant emissions), however, can be calculated from the available data. The process for calculation of these benefits is described below and the results are presented in Table 8. Other benefits, such as land impacts due to reduced need for roadway construction or expansion, reductions in water pollution due to reduced vehicle use, etc., cannot be quantified from the available data but are nevertheless real.

- $\mathrm{CO}$ reduced is derived, for each year, by:

\section{9 grams per mile $x$ miles reduced per commuter $x \#$ of commuters 454 grams per pound}

- $\mathrm{HC}$ reductions are derived, for each year, by:

\section{7 grams per mile $\mathrm{x}$ miles reduced per commuter $\mathrm{x}$ \# of commuters 454 grams per pound}

- NO reductions are derived, for each year, by:

1.9 grams per mile $\mathrm{x}$ miles reduced per commuter $\mathrm{x}$ \# of commuters 454 grams per pound

- $\mathrm{CO}_{2}$ reductions are derived, for each year, by:

1.2 pounds per mile $\mathrm{x}$ miles reduced per commuter $\mathrm{x}$ \# of commuters 
Most of the factors used in these calculations are provided by the EPA (EPA, www.epa.gov/otaq/ann-emit.htm).

\section{TDM Initiatives}

Companies adopt TDM initiatives when the traffic congestion in the area becomes an issue. Table 9 shows the CUTR local business surveys had a very low response rate. This means that the few percentage point differences from year to year can be well within the margin of error of the surveys. Consequently, all you can probably say about the results is that there is no observable trend. This could be explained by the fact that employer programs such as compressed workweeks, flextime, telecommuting, etc., are influenced by many factors in addition to TDM efforts and local traffic congestion.

\begin{tabular}{||l|c|c|c|c|l||}
\hline \multicolumn{7}{|c||}{ TDM Initiative Results } \\
\hline Performance Measure & 1997 & 1998 & 1999 & 2000 & How Measured \\
\hline $\begin{array}{l}\text { Percentage of employers } \\
\text { with compressed work } \\
\text { week programs }\end{array}$ & $11 \%$ & $12 \%$ & $16 \%$ & $11 \%$ & LB Surveys $^{\mathrm{a}}$ \\
\hline $\begin{array}{l}\text { Percentage of employers } \\
\text { with flextime programs }\end{array}$ & $15 \%$ & $13 \%$ & $16 \%$ & $17 \%$ & LB Surveys $^{\mathrm{a}}$ \\
\hline $\begin{array}{l}\text { Percentage of employers } \\
\text { with a telecommuting } \\
\text { program }\end{array}$ & $5 \%$ & $3 \%$ & $4 \%$ & $8 \%$ & LB Surveys $^{\mathrm{a}}$ \\
\hline $\begin{array}{l}\text { Percentage of commuters } \\
\text { walking or biking to } \\
\text { work }\end{array}$ & $1 \%$ & $0.9 \%$ & $0.9 \%$ & $1.1 \%$ & GP Surveys $^{\mathrm{a}}$ \\
\hline
\end{tabular}

Table 9: TDM Initiatives Data

${ }^{a}$ Data from CUTR Surveys 1997, 1998, 1999 and 2000 


\section{Chapter 5}

\section{Company Case Studies}

\section{Case Studies}

SFCS works with individual companies within the tri-County region to promote successful TDM initiatives to employees. Initial employer outreach efforts consist of either a mailing campaign or site visitations. Mailing campaigns usually target certain zip codes along major highways, Chamber of Commerce mailing lists or professional associations. The goal is to schedule an event during which staff can speak with employees during a defined time period, answering any questions that relate to available commute options. While it is true that SFCS will work with any company, regardless of size, marketing efforts such as direct mailings are targeted at companies employing more than 100 employees. This is done because of the need to reach a larger audience with limited resources.

The following case studies showcase four companies in Miami-Dade County and two companies in each of Broward and Palm Beach Counties. A greater number of case studies are included for Miami-Dade County because of its greater population and because it is the host of two TMIs. Each case study includes the demographics of the company, how many applicants are in the regional rideshare database, an "employee transportation profile", available transit service and site-specific TDM initiatives.

The employee transportation profile looks specifically at: transportation modes; the average commute in miles; ERH program applicants; daily monetary savings from ridesharing; and how 
many applicants matched with others and have the opportunity to begin ridesharing. Figures 4,6 , $8,10,12,14,16$ and 18 all display a base line of this information as it was entered into the regional rideshare database. To determine the average commute mileage for applicants, maps for each company were created. The following table is an example of how the average commute mileage is calculated:

\begin{tabular}{|c|c|c|}
\hline \multicolumn{3}{|c|}{ COMPUTING AVERAGE COMMUTE MILEAGE } \\
\hline Miles & Number of Applicants & Total Applicants x Miles \\
\hline 5 & 19 & 95 \\
\hline 10 & 29 & 290 \\
\hline 15 & 33 & 495 \\
\hline 20 & 47 & 940 \\
\hline 25 & 8 & 200 \\
\hline 30 & 5 & 150 \\
\hline 35 & 4 & 140 \\
\hline 40 & 0 & 0 \\
\hline 45 & 1 & 45 \\
\hline 50 & 0 & 0 \\
\hline 70 & 1 & 70 \\
\hline Column Totals & 147 & 2,425 \\
\hline Average Miles per Applicant & & 16.5 \\
\hline
\end{tabular}

Table 10: Computing Average Commute Mileage

Daily and yearly monetary savings from carpooling are calculated by taking the average commute for the applicants and multiplying that by the average cost per mile of $\$ .29$. Finally, matched applicants who have the opportunity to form a carpool are chosen on the basis of the home and 
work place mile definitions in Table 11. These radii have been established within the rideshare database program since 1998:

\begin{tabular}{|c|c|c||}
\hline \multicolumn{2}{|c||}{ HOME AND WORK SEARCH RADII } \\
\hline Miles to Work & Home & Wearch Radii (Miles) \\
\hline $0-1$ & 0.25 & 0.25 \\
\hline $1-5$ & 0.5 & 0.5 \\
\hline $5-10$ & 1.5 & 1.5 \\
\hline $10-15$ & 1.5 & 1.5 \\
\hline $15-20$ & 2 & 2 \\
\hline $20+$ & 5 & 5 \\
\hline
\end{tabular}

Table 11: Home and Work Mile Search Radii

Search radii have been set by FDOT and SFCS based on population densities and achieving a higher match rate for applicants. Applicants' information is typed into the BACSCAP program, a ride matching software program developed by Florida State University, whereby a match list is generated and mailed out to the individual. It is then the decision of the applicant if (s)he wants to begin carpooling with the individuals on the list.

A component of the case studies is a discussion of transit links that are available for those individuals who live along those service lines. Incentive programs are encouraged to utilize transit to ensure participation. For example, TriRail has an Employee Discount Program whereby monthly passes can be purchased for $\$ 60$. Miami-Dade Transit Agency (MDTA) has a "Corporate Incentive Program" whereby a company can purchase between 5 and 99 monthly passes for $\$ 54.00$ each (regularly $\$ 60.00$ ) and over 100 passes for $\$ 52.00$ each. Finally, Broward 
County Transit (BCT) has a program called TransPass whereby monthly passes of unlimited rides on the entire system can be bought for $\$ 32.00$ /month, whereas one trip one way is $\$ 1.00$. At this time PalmTran does not have an incentive program for employers.

TDM practices at the facility are the final component of the case study. To recommend the most appropriate TDM initiatives to a company, SFCS' staff must be familiar with the needs of employees. This is accomplished at the SFCS event. Individuals are encouraged to sign up into the regional rideshare database to find a carpool partner and take advantage of the ERH program (for those using an alternative mode of transportation). Once the event has taken place the information is gathered and a report is generated to present to the employer. Within this report TDM strategies are suggested to the employer to adopt at the facility. The following are TDM initiatives that can be adopted:

- Appoint an Employee Transportation Coordinator (ETC).

- Provide contacts of surrounding businesses to increase rideshare opportunities for the area.

- Link up to SFCS ' web page at www.commuterservices.com/sf.

- Schedule follow-up events and other promotions to increase the employee participation rate.

- Actively participate in AWTMI or DMTMI activities such as advisory group meetings if applicable.

- Include rideshare applications and appropriate transit route information in employee orientation materials.

- Provide secured and covered parking for bicyclists.

- Provide preferential parking for carpoolers and vanpoolers.

- Make transit information more readily available by displaying appropriate transit routes and SFCS' $1-800$ number in high visibility areas. 
- Participate in the appropriate transit agency's employee discount program if available.

- Provide TDM information in the employee and employer newsletters, if available, by requesting monthly "Commuter News" articles.

- Promote the Regional ERH program by means of paycheck stuffers, articles and new hire package inserts.

- Hold vanpool meetings to promote the Miami-Dade Vanpool program.

- Provide work hour adjustments such as staggered work hours, compressed work schedules and flextime to assist with ridesharing arrangements.

- Promote telecommuting to applicable employees.

These initiatives are implemented with the guidance and support of SFCS ' staff. The employer is encouraged to appoint an ETC to be the point person for SFCS staff to work with on implementing TDM initiatives. The ETC usually works in the Human Resources department and devotes a percentage of their time if not all their time, depending on the severity of traffic congestion on site. 


\section{Baptist Hospital}

Baptist Hospital is a private hospital located at 8900 North Kendall Drive in Miami-Dade County with approximately 6,000 employees. SFCS events that have been held at the site since November 10, 1999 have resulted in 407 applicants. This represents $7 \%$ of the total work force.

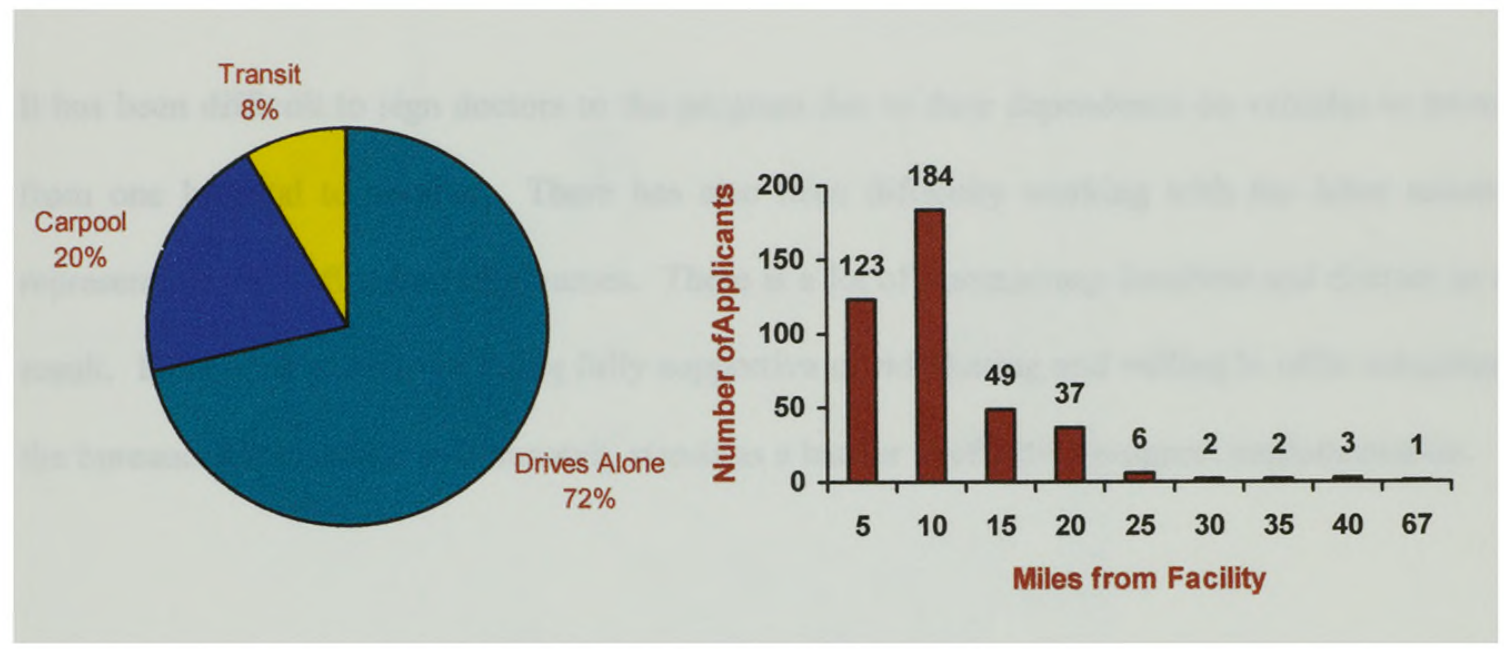

Figure 4: Baptist Hospital Applicants' Mode Percentages and Commute Miles

As shown in Figure 483 individuals (20\%) carpool or vanpool and 34 individuals (8\%) ride transit and have been registered in the ERH program. As a result of the rideshare database matching, 190 applicants (47\%) matched with others. The average commute, taken from information from Figure 5, for the 407 applicants is 21.6 miles (10.8 miles each direction). Taking this into account, it is estimated that one carpool can reduce 21.6 miles and save $\$ 5.29$ per person per day (this figure includes the driver) and $\$ 1,296.00$ for the year (245 working days).

Baptist Hospital operates 24-hours per day with staggered work shifts. To entice employees, tax benefits are being provided for employees who ride transit by deducting pre-tax dollars from their salaries for their transit passes. In addition, they are subsidizing vanpool riders by paying up to $\$ 60.00$ of the total fee. Figure 5 shows the distribution of applicants. It is apparent that there are 
a lot of individuals who could join a vanpool from the west and take advantage of the vanpool subsidy. To reward those individuals who carpool or vanpool the Hospital provides provide preferential parking in the most convenient spaces on the campus. Baptist Hospital also supports flextime for those who carpool and vanpool. Finally, to disseminate information the "Commuter News" article is included in the Hospital's employee newsletter.

It has been difficult to sign doctors to the program due to their dependence on vehicles to travel from one hospital to another. There has also been difficulty working with the labor unions representing the staff, especially nurses. There is a lot of bureaucracy involved and distrust as a result. Even with executives being fully supportive of ridesharing and willing to offer subsidies, the bureaucratic machine unfortunately stands as a barrier to effective program implementation. 


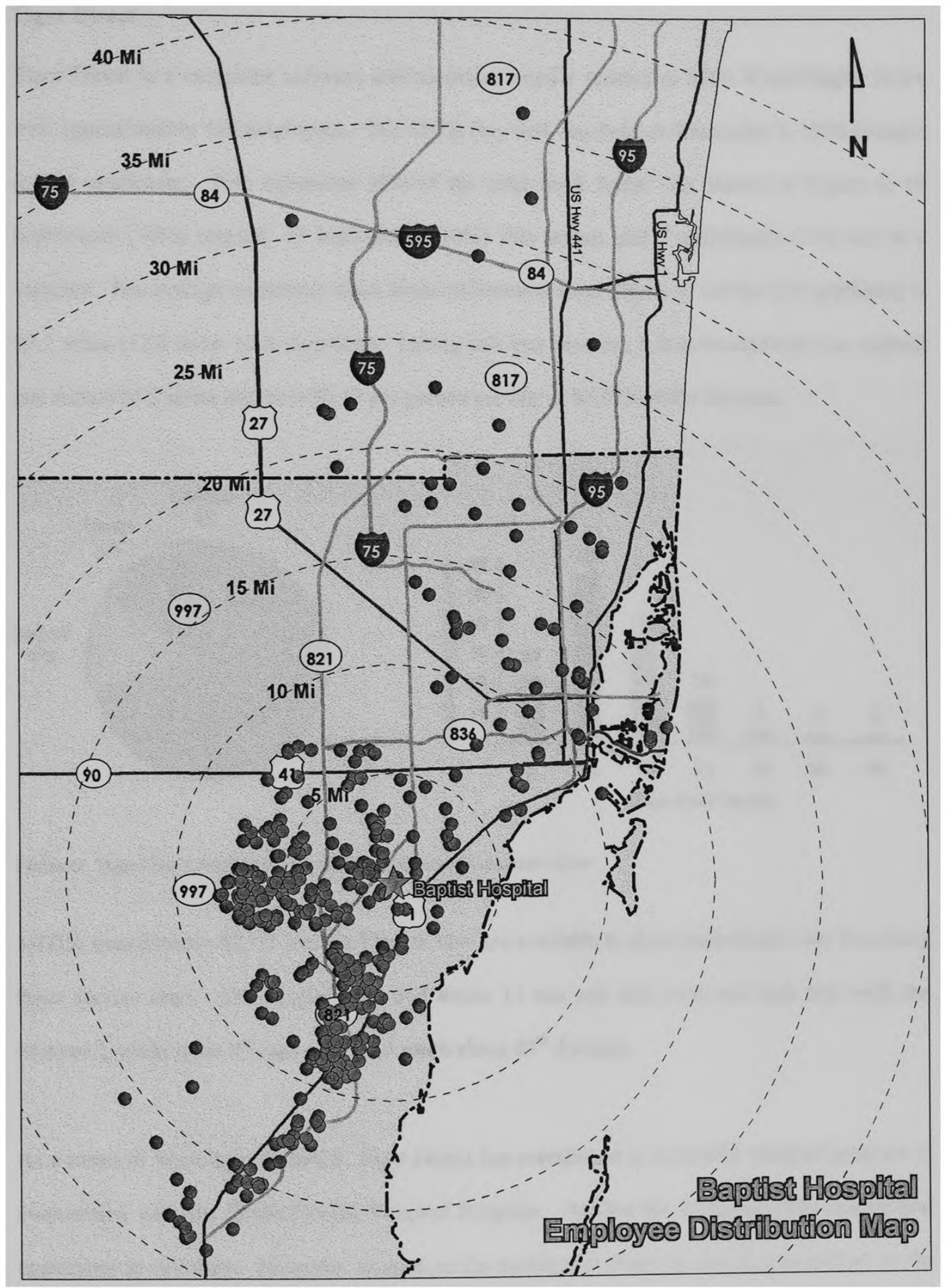

Figure 5: Baptist Hospital Applicant Distribution Map 


\section{Tiger Direct}

Tiger Direct is a computer software and hardware retailer located at 8700 West Flagler Drive with approximately 450 employees. The SFCS Day that was held on December 3, 1998 brought in 134 applicants. This represents $30 \%$ of the total work force. As shown in Figure 6, 19 individuals (14\%) carpool, 13 individuals (10\%) ride transit and 7 individuals $(5 \%)$ are in a vanpool. The average commute, taken from information from Figure 7, for the 134 applicants is 25.2 miles (12.6 miles each direction). Taking this into account, it is estimated that one carpool can reduce 25.2 miles and save $\$ 6.17$ per person per day or $\$ 1,512.00$ for the year.
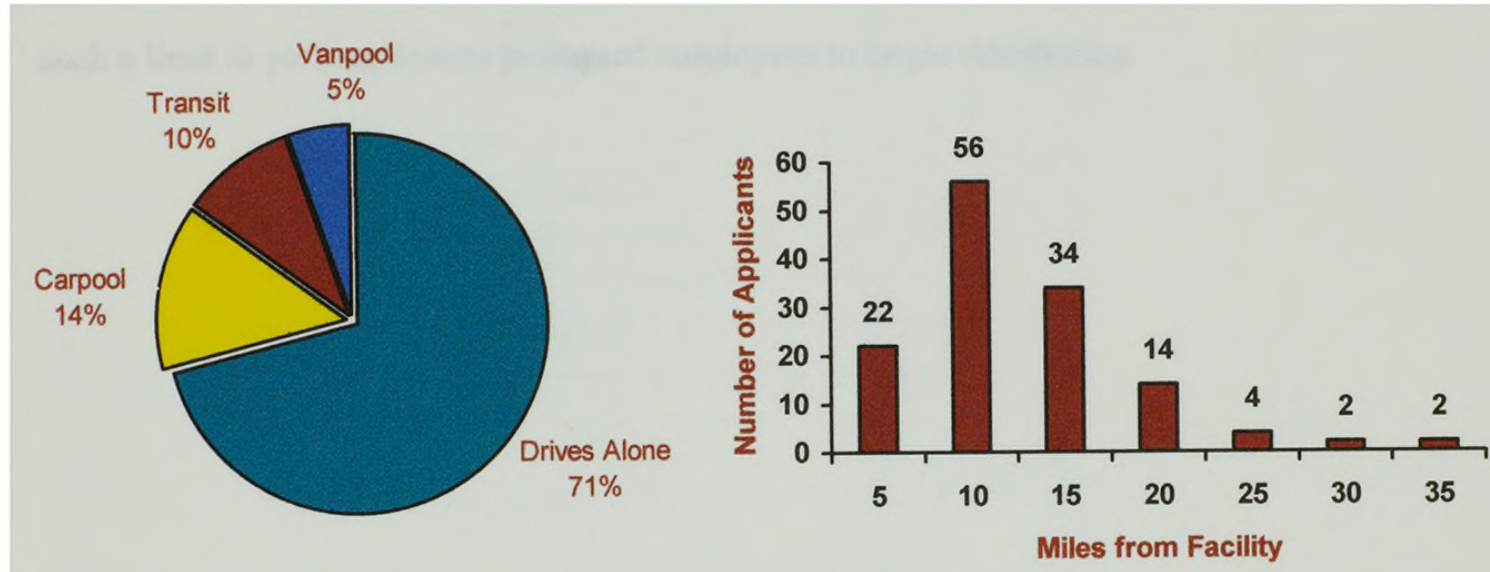

Figure 6: Tiger Direct Applicants' Mode Percentages and Commute Miles

MDTA transit routes 87,11 and the Flagler Max are available to those individuals who live along these service lines. The Flagler Max and Route 11 run east and west and both link with the Metrorail, while route 87 runs north and south along $87^{\text {th }}$ Avenue.

As a result of working with SFCS, Tiger Direct has established a successful vanpool program in conjunction with the South Florida Vanpool Program. At first the company only encouraged employees to rideshare. However, as soon as the parking lot filled up and people parked on the grass, the Office Park Management team called tow trucks to tow those parked illegally. This 
created hostility and aggressive behavior within the parking lot and towards employers. Utilizing the data presented in Figure 7, Tiger Direct not only encouraged employees to participate in the Vanpool Program but also began subsidizing the cost of the fare and providing preferential parking to ensure that those individuals have convenient parking spaces. Finally, they disseminated rideshare information by providing the monthly "Commuter News" article in their employee newsletter and included rideshare applications in their employee orientation materials.

Since the employees took interest in ridesharing, vanpools have increased dramatically from no vans to 6 vans in service carrying an average of 42 people. In this case study, a direct impact, such a limit in parking spaces prompted employees to begin ridesharing. 


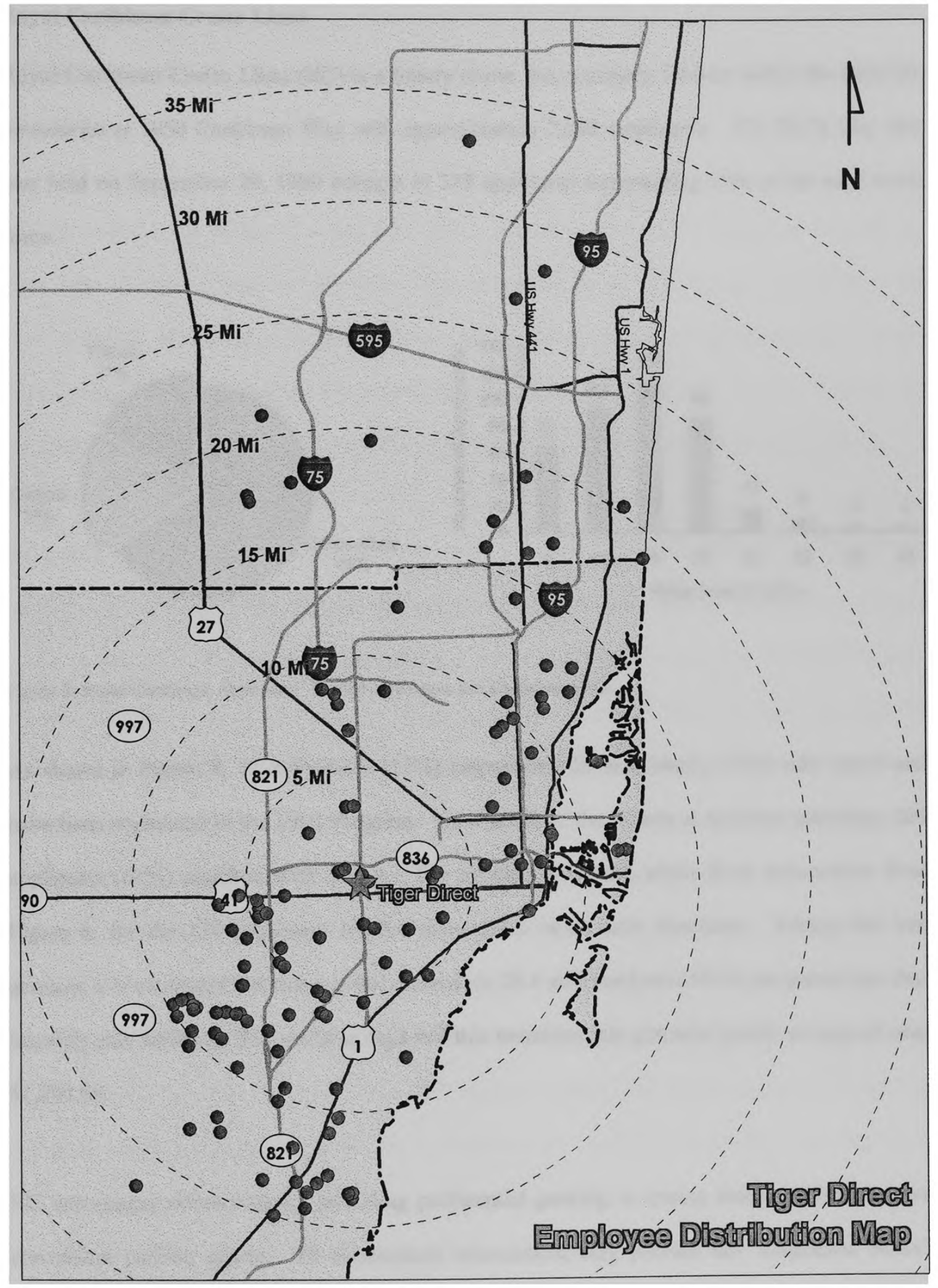

Figure 7: Tiger Direct Applicant Distribution Map 


\section{Royal Caribbean Cruise Lines}

Royal Caribbean Cruise Lines (RC) is a luxury cruise ship company located within the DMTMI boundaries at 1050 Caribbean Way with approximately 2,200 employees. The SFCS Day that was held on September 29, 1999 brought in 328 applicants representing 15\% of the total work force.

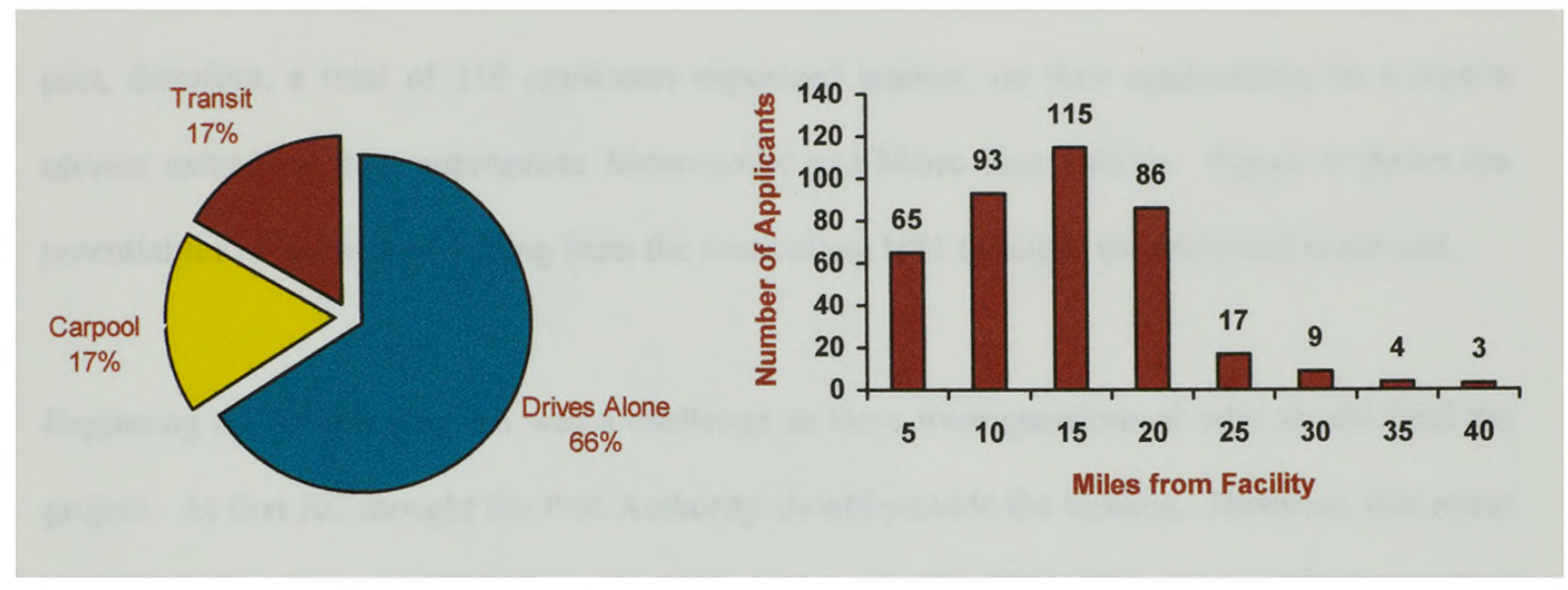

Figure 8: Royal Caribbean Applicants' Mode Percentages and Commute Miles

As shown in Figure 8, 57 individuals (17\%) carpool and 55 individuals (17\%) ride transit and have been registered in the ERH Program. As a result of the rideshare database matching, 201 applicants $(61 \%)$ matched with others. The average commute, taken from information from Figure 9, for the 328 applicants is 28.4 miles (14.2 miles each direction). Taking this into account, it is estimated that one carpool can reduce 28.4 miles and save $\$ 6.96$ per person per day. Multiply this saving by 245 working days and this translates into potential yearly savings of over $\$ 1,705.00$.

$\mathrm{RC}$ encourages ridesharing by providing preferential parking to ensure those individuals have convenient parking spaces. To disseminate information, they provide the "Commuter News" article in their employee newsletter and include rideshare applications in their employee 
orientation materials. In addition, they supported the DMTMI by holding a Transportation Committee meeting on one of their cruise ships to draw in the downtown Miami business community.

MDTA routes $3,16,48,95, \mathrm{C}, \mathrm{S}$ and the Flagler MAX as well as the Metrorail are available to those who live along these service lines. However, these transit lines do not go directly to the port, therefore, a total of 210 applicants expressed interest, on their applications, in a shuttle service extending from appropriate Metromover and Metro Bus stations. Figure 9 shows the potential for an individual driving from the south along US1 to utilize the Metrorail is not met.

Beginning the shuttle program was a challenge as there were questions of who should fund the project. At first RC thought the Port Authority should provide the funding. However, that never came to fruition due to political constraints and the unwillingness of the Port Authority to fund private employees' transportation. RC then attempted to contact MDTA. This also did not produce results due to MDTA not expanding routes if there was not enough "interest" for a specific route. Even though there was in this case, MDTA had in the past attempted to provide a route to the Port, however, it had failed to attract enough riders and cost a lot of money. Therefore, MDTA was hesitant to try something that had failed in the past. Finally, after three years of failed negotiations, RC provided funding for two shuttles to run to and from the site to appropriate transit connections, especially the Metrorail. This process provided an important lesson to SFCS as they expended time and research exploring different avenues for RC. A company or site's transportation history is important and must be known before attempting to fund a route or project. 


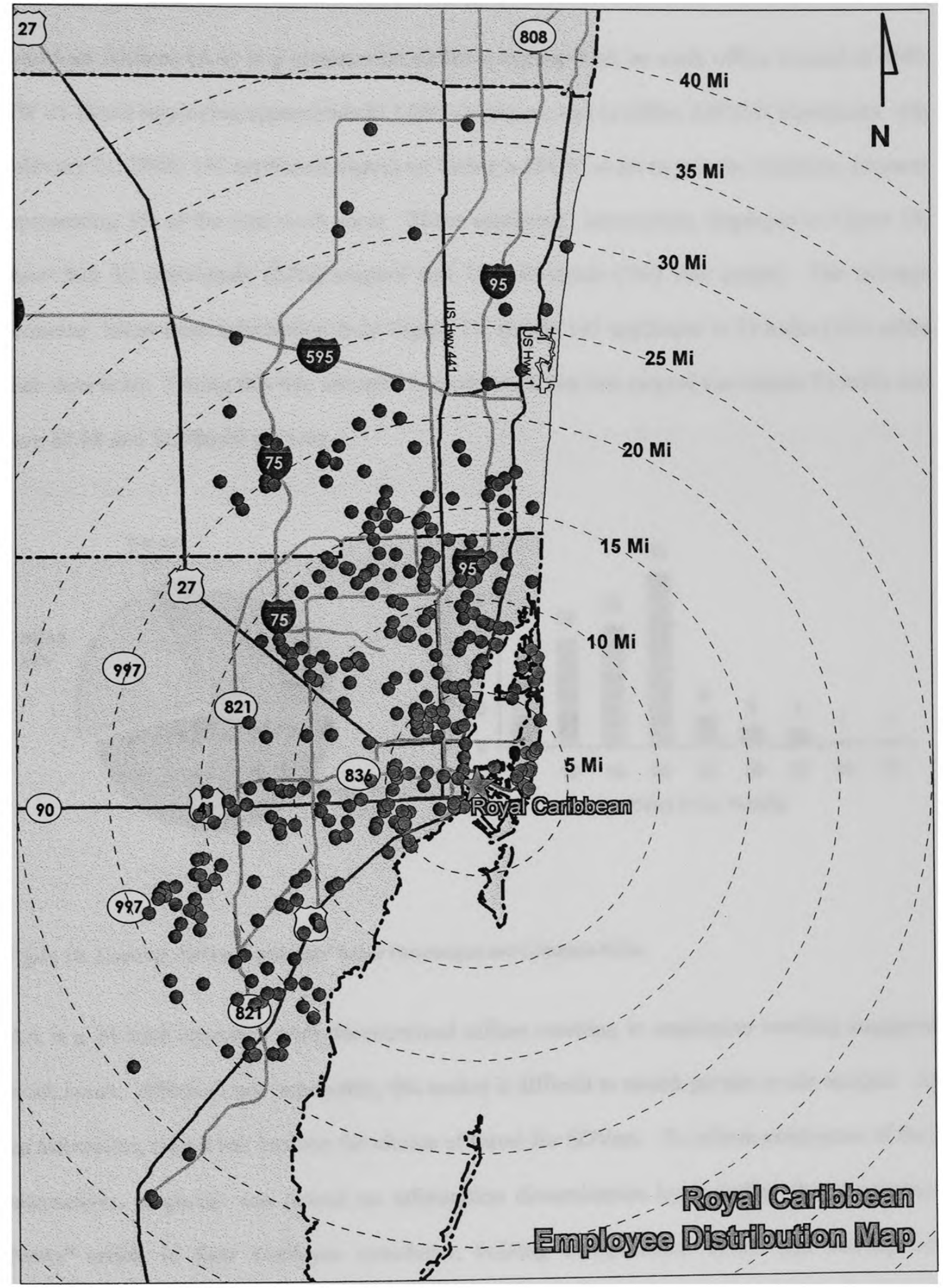

Figure 9: Royal Caribbean Applicant Distribution Map 


\section{American Airlines}

American Airlines (AA) is a commercial airline company with its main office located at 4501 NW 21 Street employing approximately 5,000 employees and is within AWTMI boundaries. On February 21, 2000, 147 applicants signed up during a SFCS' event to join the rideshare database representing $3 \%$ of the total work force. These applicants' information, displayed in Figure 10, show that 32 individuals $(22 \%)$ carpool and 11 individuals (7\%) ride transit. The average commute, taken from information from Figure 11, for the 147 applicants is 33 miles (16.5 miles each direction). Taking this into account, it is estimated that one carpool can reduce 33 miles and save $\$ 8.08$ and $\$ 1,980.00$ per year.

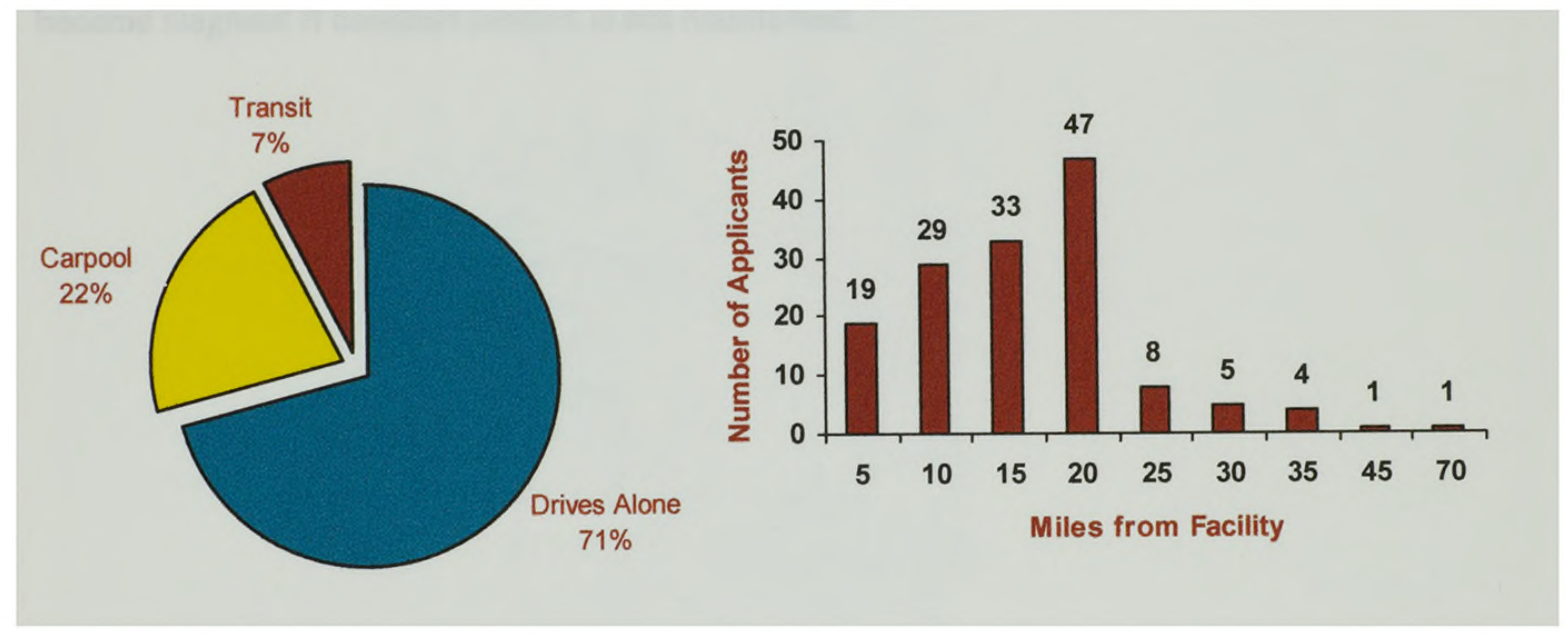

Figure 10: American Airlines Applicants' Mode Percentages and Commute Miles

AA is a 24-hour operation with decentralized offices resulting in employees working staggered work hours. Although not impossible, this makes it difficult to match people to one another. As an alternative, transit has become the choice of travel for SOVers. To inform employees of their alternatives, emphasis was placed on information dissemination by including the "Commuter News" article in their employee newsletter, holding transportation events and mailing out paycheck stuffers. After many discussions with employees at the site, it was confirmed that there 
were missing links in the transit system. As a result, American Airlines is participating in the AWTMI shuttle study to increase transit ridership. It has been determined that the route must serve those who work during peak rush hours since night shift employees travel during less congested times.

AA, while it has supported the program, does not wish to put forth monetary resources to solidify TDM initiatives. They have always been hand-held by the Airport Authority who has strict rules and restrictions placed on them. It took a long time to develop a trusting relationship with AA and it needs to be constantly nourished. This is a company that will allow their TDM program to become stagnant if constant contact is not maintained. 


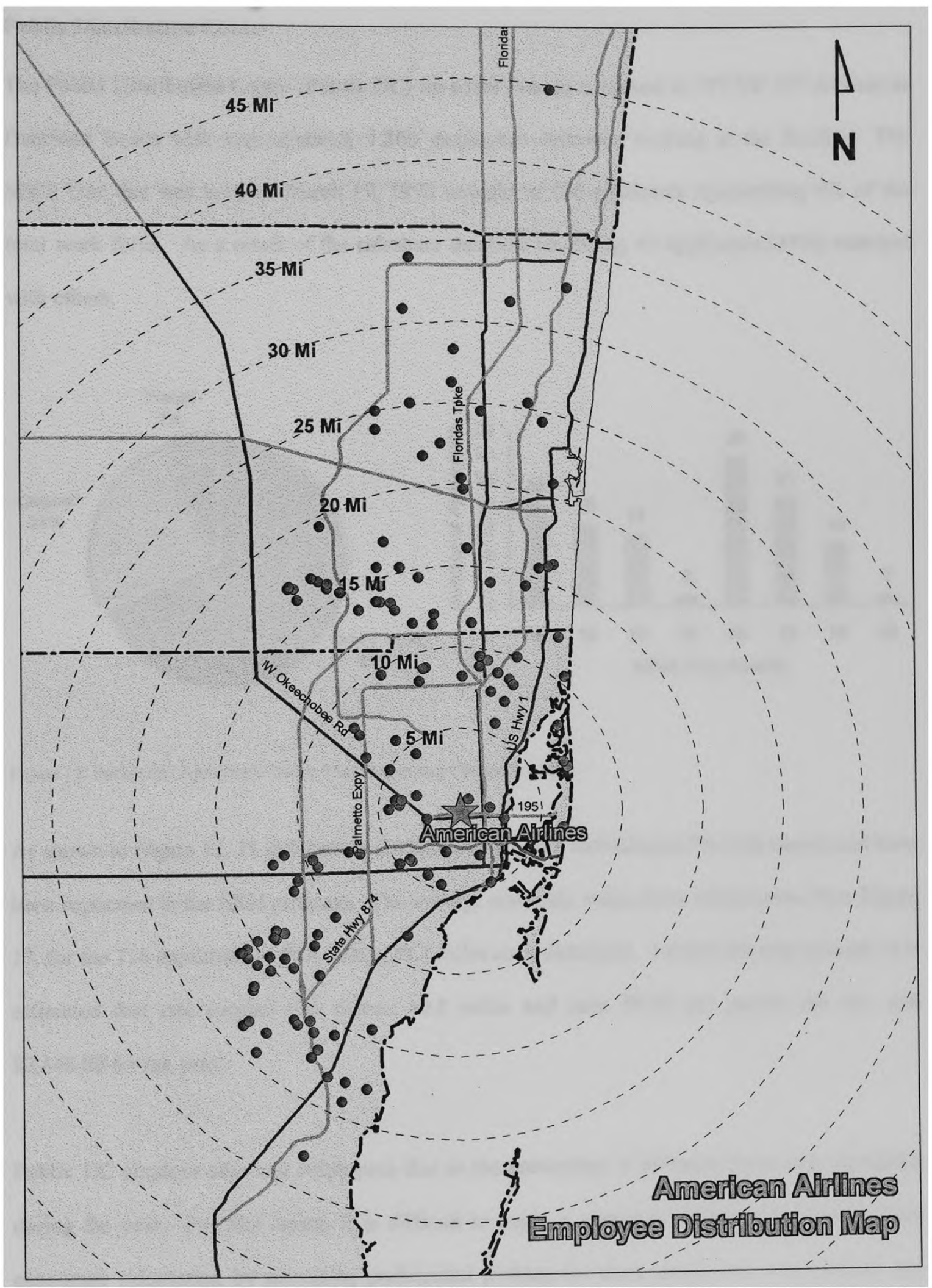

Figure 11: American Airlines Applicant Distribution Map 


\section{Publix Distribution Center}

The Publix Distribution Center (Publix DC) for south Florida is located at $777 \mathrm{SW} 12^{\text {th }}$ Avenue in Deerfield Beach with approximately 1,300 employees currently working at the facility. The SFCS Day that was held on March 19, 1998 brought in 116 applicants representing $9 \%$ of the total work force. As a result of the rideshare database matching, 47 applicants $(41 \%)$ matched with others.

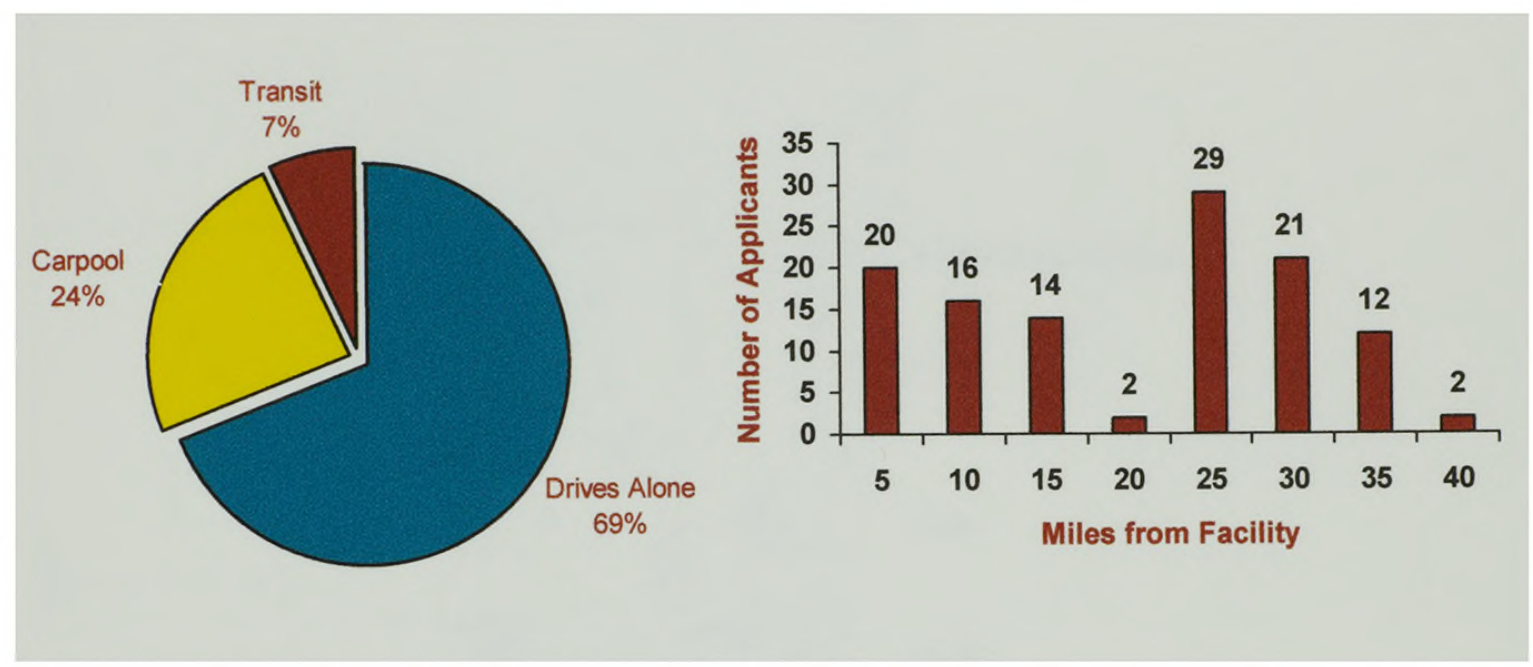

Figure 12: Publix DC Applicants' Mode Percentages and Commute Miles

As shown in Figure 12, 28 individuals (24\%) carpool and 8 individuals (7\%) ride transit and have been registered in the ERH program. The average commute, taken from information from Figure 13 , for the 116 applicants is 40.8 miles (20.4 miles each direction). Taking this into account, it is estimated that one carpool can reduce 40.8 miles and save $\$ 9.99$ per person per day and $\$ 2,448.00$ for the year.

Publix DC employs seasonal employees due to the harvesting of different fruits and vegetables during the year. For this reason it is difficult to begin a consistent rideshare program. They encourage ridesharing by providing preferential parking for those employees who carpool and 
they also include rideshare applications in their employee orientation materials. In all, there is a lack of support and enthusiasm from upper management due to a high percentage of seasonal employment. Because a lot of the employees are not permanent there is a lack of loyalty and motivation to participate in extra activities. However, the importance lies in the education of their commuting options as they move on to other jobs and one day possibly a permanent one. 


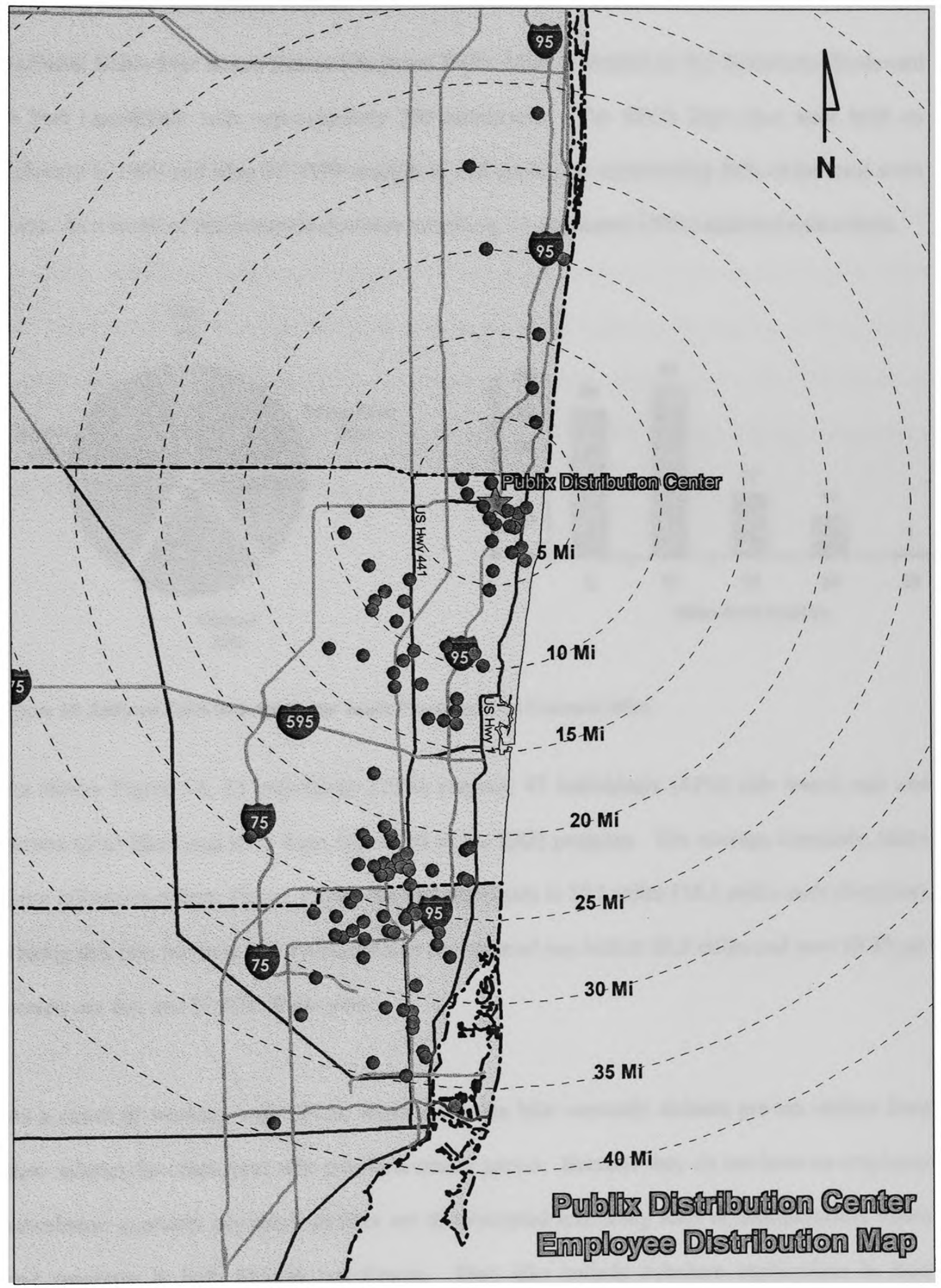

Figure 13: Publix DC Applicant Distribution Map 


\section{Radisson Bahia Mar Beach Resort}

Radisson Bahia Mar Beach Resort (Radisson Bahia Mar) is located at 801 Seabreeze Boulevard in Fort Lauderdale with approximately 300 employees. The SFCS Days that were held on February 5, 1999 and May 27, 1999 brought in 115 applicants representing 38\% of the total work force. As a result of the rideshare database matching, 35 applicants (30\%) matched with others.

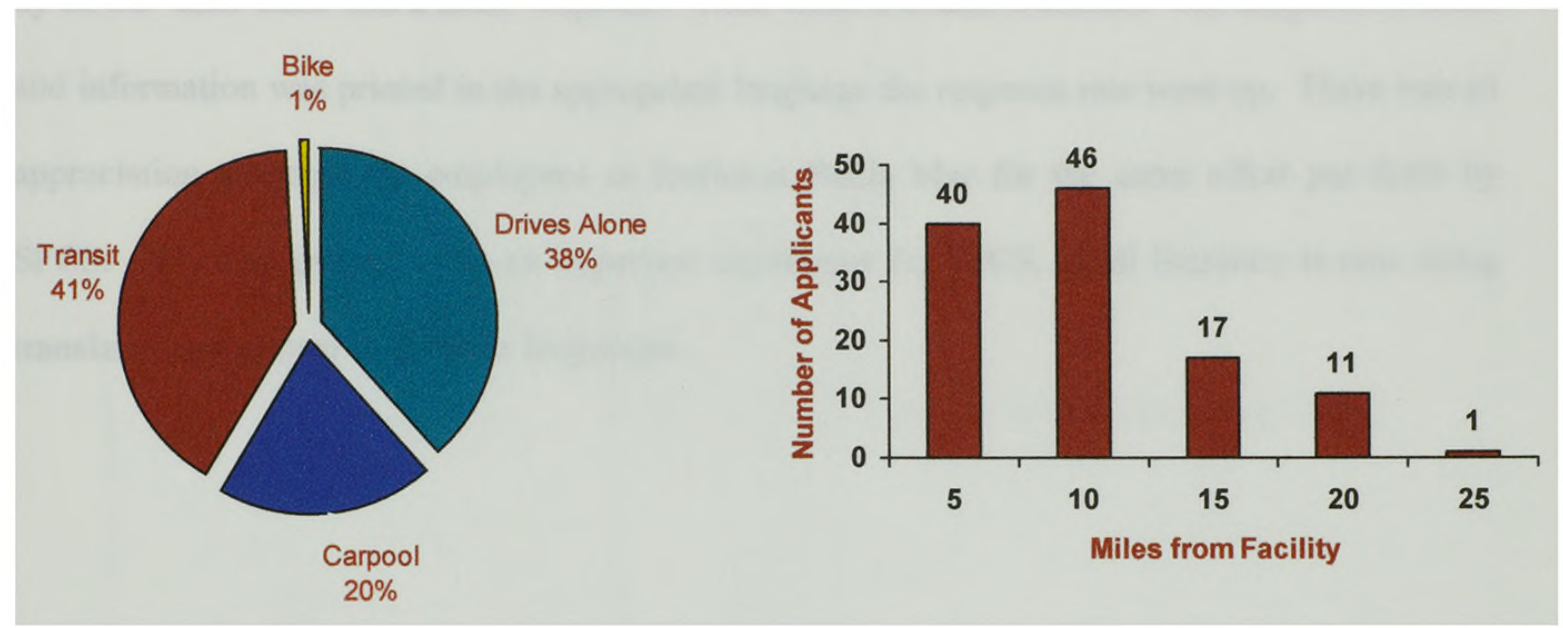

Figure 14: Radisson Bahia Mar Applicants' Mode Percentages and Commute Miles

As shown Figure 14, 23 individuals (20\%) carpool, 47 individuals (41\%) ride transit and one person $(1 \%)$ bikes and have been registered in the ERH program. The average commute, taken from information from Figure 15, for the 115 applicants is 20.2 miles (10.1 miles each direction). Taking this into account, it is estimated that one carpool can reduce 20.2 miles and save $\$ 9.89$ per person per day and $\$ 2,423.00$ per year.

As a result of working with SFCS, Radisson Bahia Mar currently deducts pre-tax dollars from their salaries for employees who purchase transit passes. Because they do not have an employee newsletter, quarterly paycheck stuffers are disseminated informing staff of transportation issues and programs in both English and Creole. They also include rideshare applications in their 
employee orientation materials to help them find a carpool partner or to register them in the ERH program if they are using an alternative mode of transportation upon being hired.

SFCS has expanded its practice to print all materials not only in English and Spanish, but also Creole as a result of working with Radisson Bahia Mar. At first, when visitations were conducted by SFCS' staff there was a small response. Then when a Creole translator was temporarily hired and information was printed in the appropriate language the response rate went up. There was an appreciation amongst the employees at Radisson Bahia Mar for the extra effort put forth by SFCS. This also proved to be an important experience for SFCS, as all literature is now being translated and printed in all three languages. 


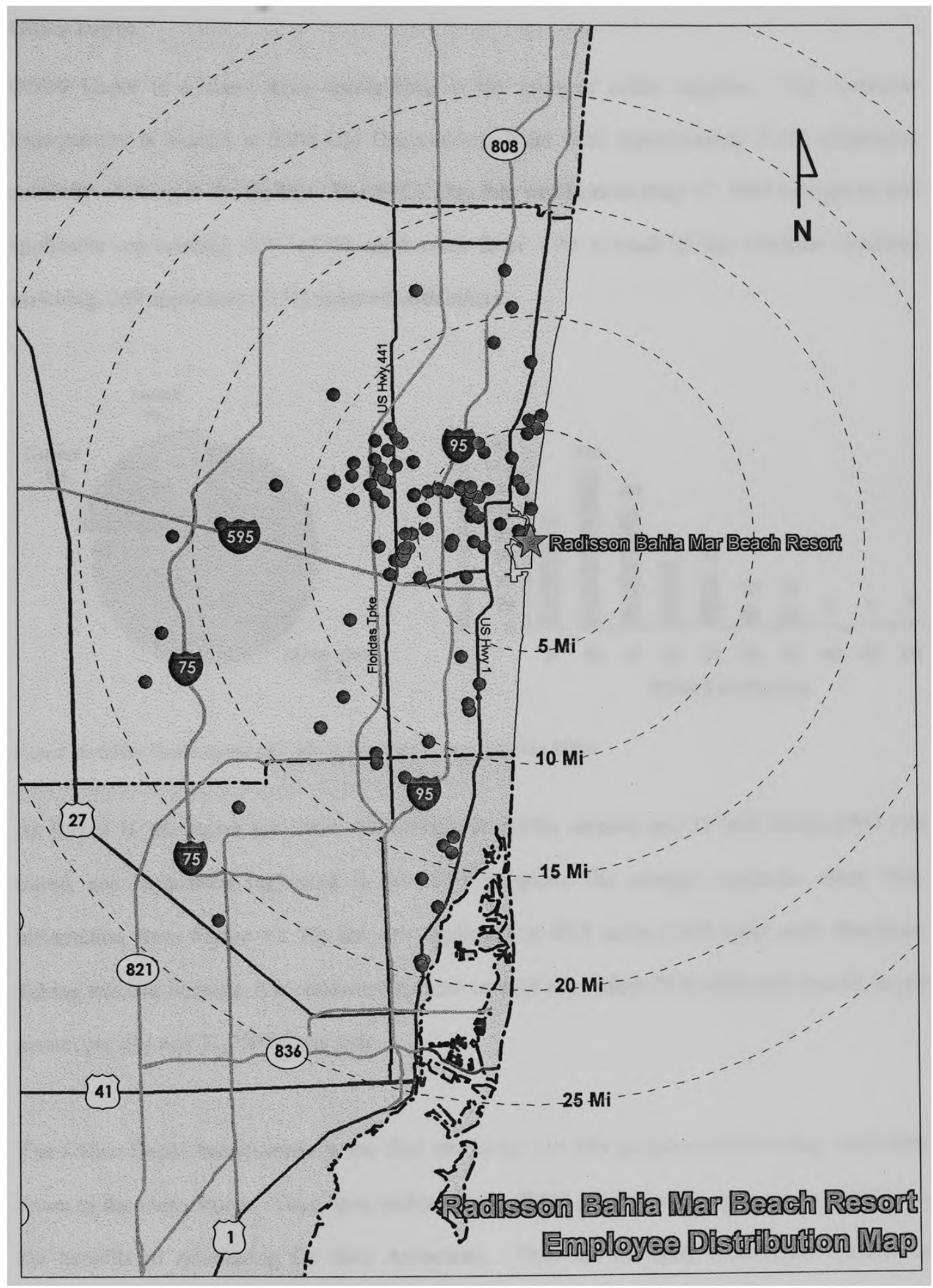

Figure 15: Radisson Bahia Mar Applicant Distribution Map 


\section{Office Depot}

Office Depot is a chain store specializing in the sales of office supplies. The corporate headquarters is located at 2200 Old Germantown Road with approximately 2,100 employees currently working at the facility. The SFCS Day that was held on May 17, 1999 brought in 444 applicants representing $21 \%$ of the total work force. As a result of the rideshare database matching, 269 applicants (61\%) matched with others.

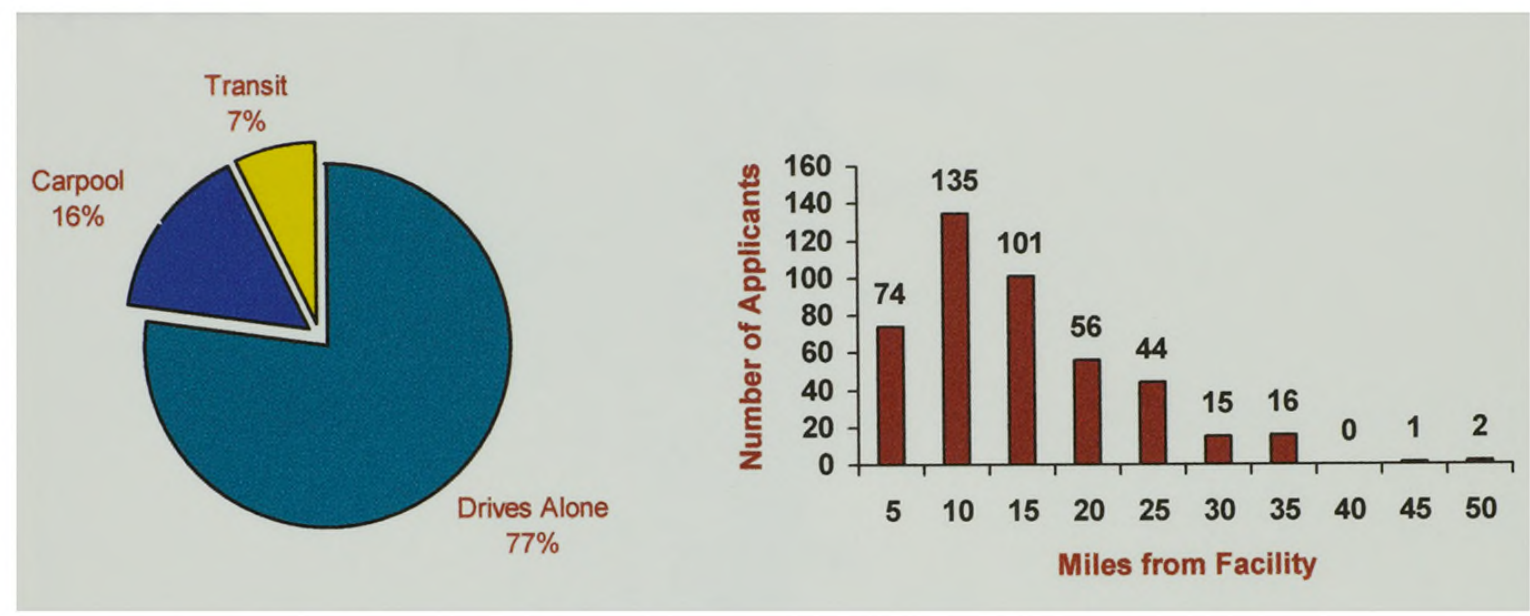

Figure 16: Office Depot Applicants’ Mode Percentages and Commute Miles

As shown in the above pie chart, 69 individuals (16\%) carpool and 32 individuals (7\%) ride transit and have been registered in the ERH program. The average commute, taken from information from Figure 17, for the 444 applicants is 29.8 miles (14.9 miles each direction). Taking this into account, it is estimated that one carpool can reduce 29.8 miles and save $\$ 7.30$ per person per day and $\$ 1,789.00$ per year.

The Office Depot headquarters is the first site to try out new programs before they send them down to the chain stores. They have embraced the SFCS program with open minds as they see the benefits of ridesharing for their Associates. They are currently researching avenues to develop a shuttle service from appropriate TriRail transit stops. To promote transit use, they have 
signed up into TriRail's EDP Program and to promote carpooling and vanpooling, they are providing preferential parking in the most convenient spots. They also find information a valuable tool, therefore, they include "Commuter News" in their employee newsletter and display a transportation board in the common area. They also promote flextime and compressed workweeks as well as telecommuting to applicable employees. Finally, they deduct pre-tax dollars for those employees who purchase transit passes. It has been fruitful working with a corporate office. 


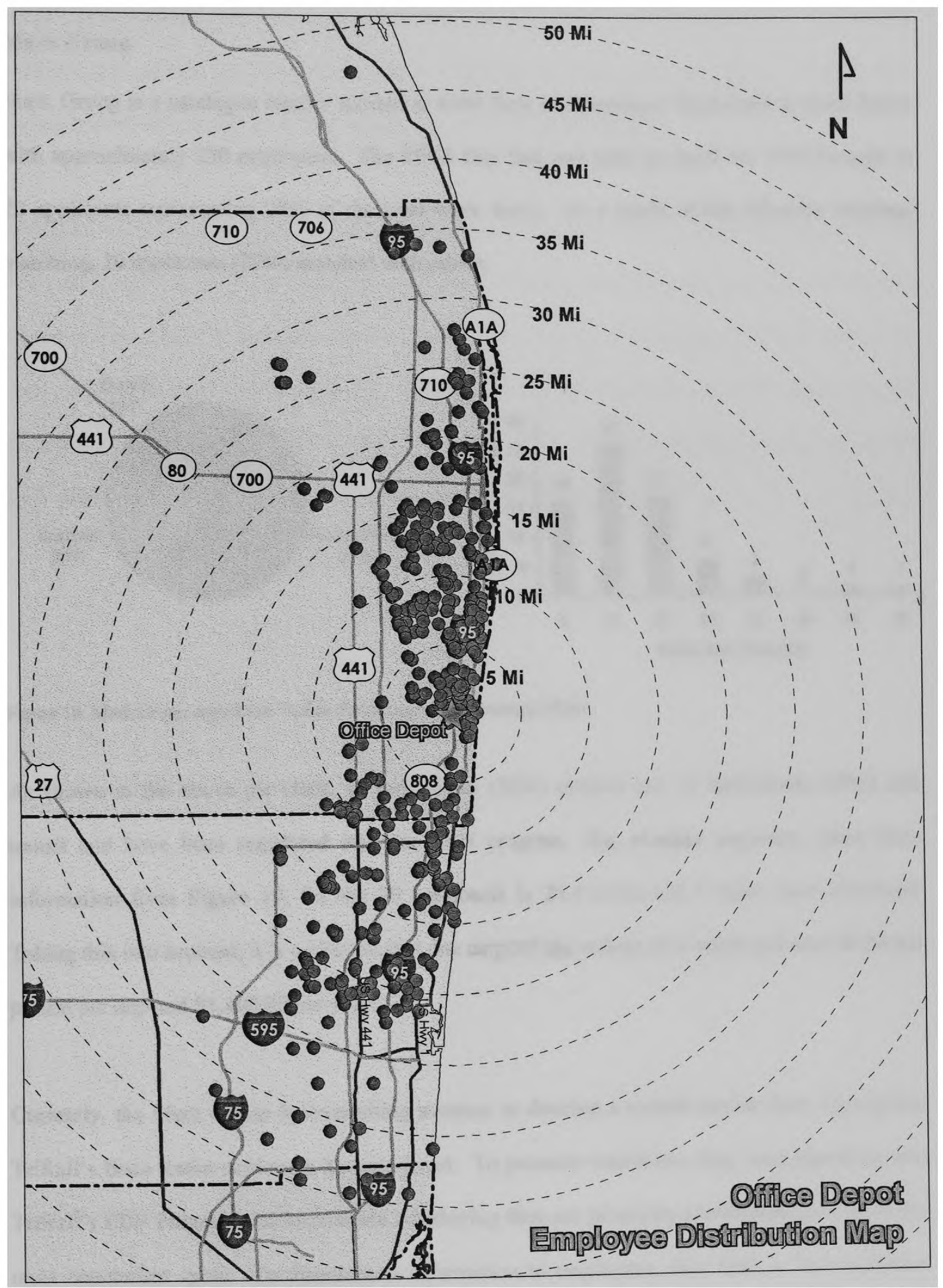

Figure 17: Office Depot Applicant Distribution Map 


\section{Mark Group}

Mark Group is a catalogue retailer located at 6500 Park of Commerce Boulevard in Boca Raton with approximately 250 employees. The SFCS Day that was held on April 14, 1999 brought in 70 applicants representing $28 \%$ of the total work force. As a result of the rideshare database matching, 20 applicants (29\%) matched with others.

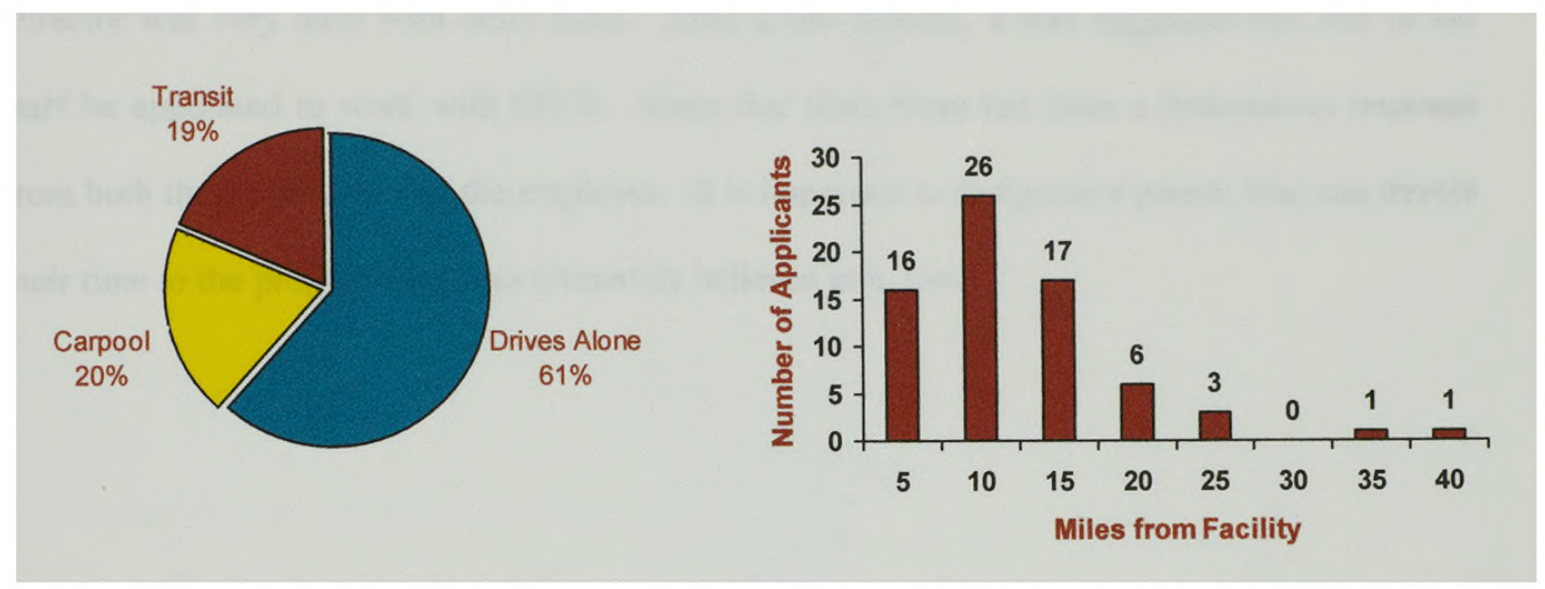

Figure 18: Mark Group Applicants' Mode Percentages and Commute Miles

As shown in the above pie chart, 14 individuals (20\%) carpool and 13 individuals (19\%) ride transit and have been registered into the ERH program. The average commute, taken from information from Figure 19, for the 70 applicants is 24.8 miles (12.4 miles each direction). Taking this into account, it is estimated that one carpool can reduce 24.6 miles and save $\$ 6.08$ per person per day and $\$ 1,490.00$ per year.

Currently, the Mark Group is researching avenues to develop a shuttle service from appropriate TriRail's Boca Raton station on Yamato Road. To promote transit use, they have signed up into TriRail's EDP Program and to promote ridesharing they are providing preferential parking in the most convenient spots. To disseminate information to employees, they have a "transportation 
board" in the cafeteria showcasing various transportation options and programs that are currently available and include the "Commuter News" article in their employee newsletter. Finally, they deduct pre-tax dollars for those employees who purchase transit passes.

The Mark Group has been an active applicant with SFCS in part due to the right person in HR being appointed the ETC. At first there was little response from the company, because the HR Director was very busy with other tasks. After a few months, it was suggested that one of her staff be appointed to work with SFCS. Since that time, there has been a tremendous response from both the employees and the employer. It is important to designate a person who can devote their time to the program and who ultimately believes in it, too. 


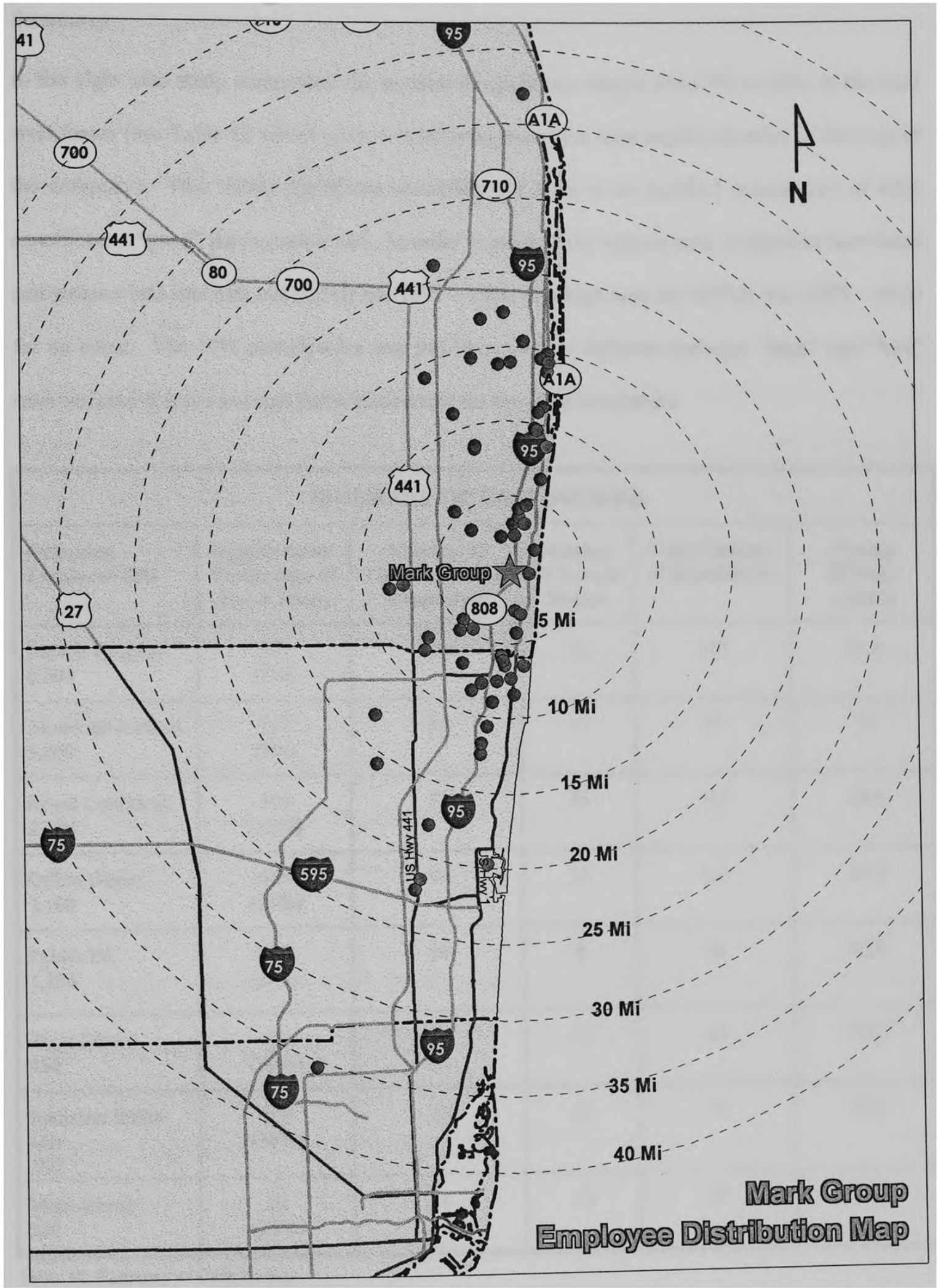

Figure 19: Mark Group Applicant Distribution Map 


\section{Summary}

In the eight case study companies, the number of applicants ranges from $3 \%$ to $38 \%$ of the total workforces (see Table 12 which gives a brief synopsis of the case studies in order of the size of the company). This shows significant variability but there is no standard determinant of what constitutes a "good" participation rate. In order to analyze the turnout data, companies have been categorized into low turn out (LTO) rate $(0 \%-19 \%)$ and high turn out (HTO) rate $(20 \%-40 \%)$ for an event. The 19\% participation rate has been used to delineate between "high" and "low" rates because it is the average participation rate for the eight companies.

\begin{tabular}{|c|c|c|c|c|c|}
\hline \multicolumn{6}{|c|}{ SUMMARY OF CASE STUDIES } \\
\hline $\begin{array}{l}\text { Company } \\
\text { Employee Size }\end{array}$ & $\begin{array}{l}\text { Applications/ } \\
\text { Percentage of } \\
\text { Work Force }\end{array}$ & $\begin{array}{l}\text { Number of } \\
\text { Carpoolers and } \\
\text { Vanpoolers }\end{array}$ & $\begin{array}{c}\text { Number } \\
\text { of Transit } \\
\text { Riders }\end{array}$ & $\begin{array}{l}\text { Total Number } \\
\text { of Ridesharers }\end{array}$ & $\begin{array}{c}\text { Average } \\
\text { Mileage } \\
\text { (miles) }\end{array}$ \\
\hline $\begin{array}{l}\text { Baptist Hospital } \\
6,000\end{array}$ & $\begin{array}{c}407 \\
(7 \%)\end{array}$ & 83 & 34 & 117 & 21.6 \\
\hline $\begin{array}{l}\text { American Airlines } \\
5,000\end{array}$ & $\begin{array}{c}147 \\
(3 \%)\end{array}$ & 32 & 11 & 43 & 33 \\
\hline $\begin{array}{l}\text { Royal Caribbean } \\
2,200\end{array}$ & $\begin{array}{c}328 \\
(15 \%)\end{array}$ & 57 & 55 & 102 & 28.4 \\
\hline $\begin{array}{l}\text { Office Depot } \\
2,100\end{array}$ & $\begin{array}{c}444 \\
(21 \%)\end{array}$ & 69 & 32 & 101 & 29.8 \\
\hline $\begin{array}{l}\text { Publix DC } \\
1,300\end{array}$ & $\begin{array}{c}116 \\
(9 \%)\end{array}$ & 28 & 8 & 36 & 40.8 \\
\hline $\begin{array}{l}\text { Tiger Direct } \\
450\end{array}$ & $\begin{array}{c}134 \\
(30 \%)\end{array}$ & 26 & 13 & 39 & 25.2 \\
\hline $\begin{array}{l}\text { Radisson Bahia } \\
\text { Mar } \\
300\end{array}$ & $\begin{array}{c}115 \\
(38 \%)\end{array}$ & 23 & 47 & 70 & 20.2 \\
\hline $\begin{array}{l}\text { Mark Group } \\
250\end{array}$ & $\begin{array}{c}70 \\
(28 \%)\end{array}$ & 14 & 13 & 27 & 24.8 \\
\hline
\end{tabular}

Table 12: Summary of Case Studies 
This average was calculated by summing the individual participation rates and dividing by eight (rather than summing the number of applicants from each company and dividing by the total number of employees of all eight companies) so as not to weigh the participation rates of the larger companies disproportionately.

\section{LTO Companies}

LTO rate companies include American Airlines (3\%), Baptist Hospital (7\%), Publix DC (9\%) and Royal Caribbean (15\%). First, American Airlines has the lowest percentage probably due to the company being decentralized combined with variable work shifts. Although there was a high level of support from management, pre-promotion was difficult due to the fragmented nature of the operation. Individuals also assumed they would not find a carpool partner who worked during their specific time shift (what I have deemed the "Variable Work Hour Syndrome" or the VWH syndrome). Even though SFCS' staff explained that it was still worth attempting to find a partner, those individuals maintained a negative attitude. Sometimes, one never suspects that another individual has the same flextime schedule (especially in a fragmented company) and is always surprised when a rideshare partner is found.

Baptist Hospital is another company that has variable work shifts with some of its staff being transient. Management support has been high, which has helped with pre-promotional activities on site. However, the same VWH syndrome plagues their employees as with American Airlines' employees. Employees show certainty that another individual will not be found to carpool with! Publix Distribution Center, with approximately 1,300 employees, maintains shifts that are variable with a high percentage of staff turn over due to seasonal packaging practices. In addition, while upper management invited SFCS to hold an event, they were not as enthusiastic as 
other companies have been. This caused pre-promotional activities to be less than adequate. Finally, Royal Caribbean has been a big supporter of SFCS, yet had a mediocre employee turn out at their event. Pre-promotion was solid, but was hindered by the VWH syndrome within the company. It is evident that with these companies variable work shifts, transient employees, decentralized operations and high seasonal practices all inhibit their employees from signing up into the program regardless of management support.

\section{HTO Companies}

Companies that experienced a HTO rate included Office Depot (21\%), Radisson Beach Resort (38\%), Mark Group (28\%) and Tiger Direct (30\%). Office Depot identifies their employees as "Associates" and offers them various benefits over and above what is considered standard. There are three standard shifts in a centralized three-building complex, thus creating a "campus" style atmosphere. They held a "Transportation Fair" including all applicable transit entities and SFCS. They pre-promoted the event and announced incentive items for those individuals who would sign up into the database. At first there was some reluctance due to the VWH syndrome, but after employees were educated about the program they were more open and willing to try the program. Radisson Beach Resort has two main shifts at a centralized site. Management was supportive and promoted the event as well as provided a Creole-speaking translator for their mostly Haitian staff, increasing the turn out rate. Had they not announced that a translator would be at the event, the sign up rate would have been significantly lower due to the language barrier. The Mark Group is a smaller company with a supportive management team that heavily promoted their event. In fact, they held the event in conjunction with their quarterly "Employee Appreciation Day." Finally, Tiger Direct has focused its efforts on forming vanpools for their employees by 
subsidizing the costs and providing preferential parking. Tiger Direct management aggressively promoted and encouraged their employees to overcome the VWH syndrome.

These companies all had the support from management and although they had the VWH syndrome, management went out of their way to educate their employees on the benefits of the program. They also adopted SFCS' attitude that you should not say something does not work until it is attempted! In all, these companies maintain a positive working atmosphere that ultimately gains the trust and support of their employees.

\section{TDM Practices}

Initiated TDM practices are the next step to examine for each company. As stated previously, following their company event, the Companies work with SFCS' staff to implement TDM initiatives. The amount of support, time, effort and creativity will determine how many initiatives each company will adopt. Table 13 shows which TDM initiatives the case study companies have adopted and if there is a difference in the type or number of initiatives supported at these types of companies. As the Table 13 shows, HTO companies provide many TDM initiatives. The lack of support from management with the LTO companies cause fewer TDM initiatives to become a reality. The most popular TDM initiative adopted by these companies is promoting ridesharing efforts through information dissemination avenues followed by providing preferential parking. In all, it is important to enlist management's support to maintain successful TDM initiatives. It is also evident that the smaller to mid-size companies, with the exception of Office Depot, are all HTO companies. This is a likely result of the necessarily closer relationship between management and employees in smaller companies, and the greater likelihood in these companies that management would be actively involved in TDM initiatives. 
TDM INITIATIVES PROMOTED BY COMPANIES

\begin{tabular}{|c|c|c|c|c|c|c|}
\hline Initiative & $\begin{array}{l}\text { Pre-Tax } \\
\text { Dollars } \\
\end{array}$ & $\begin{array}{c}\text { Subsidize } \\
\text { Vanpooling }\end{array}$ & $\begin{array}{l}\text { Transit Pass } \\
\text { Program } \\
\end{array}$ & $\begin{array}{l}\text { Flextime and } \\
\text { Telecommuting }\end{array}$ & $\begin{array}{c}\text { Preferential } \\
\text { Parking }\end{array}$ & $\begin{array}{c}\text { Information } \\
\text { Dissemination }\end{array}$ \\
\hline \multicolumn{7}{|c|}{ LTO Companies } \\
\hline $\begin{array}{l}\text { Baptist } \\
\text { Hospital }\end{array}$ & $\mathrm{X}$ & & & $\mathrm{X}$ & $\mathrm{X}$ & $\mathrm{X}$ \\
\hline $\begin{array}{l}\text { Royal } \\
\text { Caribbean }\end{array}$ & & & & & $\mathrm{X}$ & $\mathrm{X}$ \\
\hline $\begin{array}{l}\text { American } \\
\text { Airlines }\end{array}$ & & & & & & $\mathrm{X}$ \\
\hline Publix DC & & & & & $\mathrm{X}$ & $\mathrm{X}$ \\
\hline \multicolumn{7}{|c|}{ HTO Companies } \\
\hline Tiger Direct & & $\mathrm{X}$ & $\mathrm{X}$ & & $\mathrm{X}$ & $\mathrm{X}$ \\
\hline $\begin{array}{l}\text { Radisson } \\
\text { Bahia Mar }\end{array}$ & $\mathrm{X}$ & & $\mathrm{X}$ & $\mathrm{X}$ & & $\mathrm{X}$ \\
\hline Office Depot & $\mathrm{X}$ & & $\mathrm{X}$ & $\mathrm{X}$ & $\mathrm{x}$ & $\mathrm{X}$ \\
\hline Mark Group & $\mathrm{X}$ & & $\mathrm{X}$ & $\mathrm{X}$ & $\mathrm{x}$ & $\mathrm{X}$ \\
\hline
\end{tabular}

Table 13: TDM Initiatives for Case Study Companies 


\section{Chapter 6}

\section{Conclusion}

\section{Analyses}

The following conclusions are based upon the research findings regarding TDM. They are in response to the objectives of this study.

\section{* Determine if the South Florida CAP is Effective}

Based on CUTR's independent evaluations from 1997 - 2000, it is apparent that the South Florida CAP has been effective through its outreach events. These events have resulted in adding applicants to its database and increasing carpooling and vanpooling (with the attendant economic and environmental benefits already discussed). The data, however, suggests that general advertising has been much less effective (if effective at all) in affecting commuter behavior. This may be the result of not enough resources being allocated to advertising to make a difference (see recommendations section below).

\section{Determine if TDM Initiatives are Advantageous}

The data generated by the case studies and evaluations indicate that TDM initiatives are generally effective once they have been implemented at a business. To be effective, however, TDM initiatives must have the support of upper management. As has already been discussed, this appears to be more likely in smaller than in larger companies.

\section{* What Initiatives Have Been Successful}

The following TDM initiatives have been the most popular at businesses:

* Preferential Parking

* Transit Pass Subsidies or Pre-tax Benefits

- Promotion of Flextime
- Subsidize Vanpool Expenses

* Promotion of the ERH Program 
The case studies show that these initiatives are the most likely to be implemented by employers. The data, however, is not sufficient to support any conclusions as to whether these would be the initiatives most preferred by the employees.

\section{* The "Free Rider"}

The analysis of the transportation mode patterns of applicants to the SFCS rideshare pool raises an important issue about the primary objective of the program. The case study figures show that a much greater than expected proportion of applicants are transit riders-an average of $12 \%$ across the eight companies, ranging from a high of $41 \%$ at Radisson Bahia Mar, to a low of $7 \%$ at American Airlines and Publix Distribution Center. In contrast, the proportion of transit riders in the United States is $5.3 \%$ and $2.0 \%$ in Florida (U.S. Census, 1990). It is clear that the average employee interested in SFCS's program is much more likely to be a transit rider already than the average Florida resident, or the average U.S. resident. One possible explanation for this phenomenon is that transit riders are more likely to be interested in the ERH program than others. As a result, transit riders may be attracted to SFCS events and sign up to the database so as to qualify for ERH assistance. This raises the question of whether the primary purpose of the program is to enhance the benefits of the south Florida public transportation system to current (as well as prospective) users, or to promote alternative transportation modes among people who are currently solo car drivers. If the latter is the primary goal of the program, the applicants who are already transit riders are "Free Riders", benefiting from a program designed to change the behavior of the solo driver. This can be construed as a drain on taxpayers' resources as the ERH program is funded by the FDOT, a state agency.

\section{* Recommendations to Implement TDM Initiatives in the Future}

After understanding the structure of a CAP, analyzing CUTR's annual evaluations and examining various SFCS' case studies, recommendations on how to improve CAP functions can be 
discussed. The following are seven achievable recommendations that can be adopted by each CAP:

1. Lobby for more monies. Each CAP should lobby their individual FDOT Districts and their local governments for money to adopt additional marketing strategies and programs. Currently, each CAPs average budget for marketing falls between $\$ 50,000$ and $\$ 100,000$. This is not enough money to target a large audience. In today's society, people are bombarded with advertisements, thus, unique marketing strategies need to come about in order to catch the public's attention. Creative marketing is the key to propelling a business or service into the limelight.

2. Expand target audiences. According to the U.S. Census Bureau, the population projection in 2005 for Florida is $16,279,000$. Of this total population, it is projected that $2,845,000$ Hispanics will be residing in Florida in 2005. For this reason the Hispanic market must be taken into consideration for marketing purposes throughout the State. In addition, the Haitian community in Miami-Dade County is significant. SFCS especially should work with community leaders to learn how to best reach their respective communities. The quarterly rideshare brochure should be trilingual to accommodate these individuals. There are cultural differences that need to be seriously considered. By not marketing to these individuals, whole communities are being left out.

3. Create interactive websites and install kiosks at transit hubs. The information highway must be taken advantage of by allowing people to automatically sign up on the web and receive an instant match list on a daily basis. This would allow people to log-on to the Internet and find someone to carpool with that specific day or find out if there is a specific vanpool that they 
could ride in. This once again takes money to achieve but can have a direct, large impact. Kiosks can also be placed in appropriate areas, i.e. malls, transit hubs and worksites where real time information on transit, carpool and vanpools can be displayed. The CAPs could rent out space on the kiosks for companies to use for advertising. This would mitigate some of the costs of keeping up the system.

4. Follow-up with companies. It is often difficult to follow-up with companies and keep track of them after their "Employee Transportation Analysis" report is presented. Staff is designated to sign up companies to achieve goals often set by the funding source. The staff concentrates on this goal, because the program will be viewed as a failure if the set goals are not met. Follow-up with each company is strained by the lack of staff needed to perform this task. Therefore, additional staff must be hired to primarily follow-up with the companies that join.

5. It is imperative that a company follows through with implementing TDM initiatives that have a wider impact. Therefore, easy to implement TDM initiatives such as preferential parking should be pursued immediately to give companies tangible results. This then gives the company incentive to adopt further TDM initiatives such as compressed workweeks, tax benefits, and telecommuting.

6. Intertwine TDM initiatives with incentives. Once a company has designated an ETC and is comfortable with implementing TDM programs, they can utilize incentives to increase participation rates. For instance a company can provide compressed workweeks for only carpoolers and vanpoolers, allow telecommuters to work flexible work schedules i.e. at night 
or during the day, provide subsidies for transit and vanpoolers or develop a shuttle for transit riders and provide them with free lunch from the company's cafeteria.

7. Develop an "Employer Transportation Network" (ETN). A "roundtable" as opposed to a speaker and audience forum can be arranged for the ETCs of each company to discuss transportation issues, innovative TDM initiatives and individual company successes and disappointments. This also gives the ETCs a place to network and exchange ideas.

8. Include TDM initiatives in Development of Regional Impact (DRI) studies and Development Orders (DO). Work with City and County governments, as well as Regional Planning Councils to include TDM language for developers to implement. Some suggestions include, but are not limited to, initiating a shuttle bus to appropriate transit stations, installing covered bus shelters and appropriate amenities, providing transit information displays, encouraging an employer subsidy program and tax incentive programs, improving pedestrian and bicycle right of ways, providing on-site day care services, providing an ETC for the development, implementing a vanpool program and providing preferential parking for carpoolers and vanpoolers.

\section{Closing Remarks}

In 1900 Colonel Albert A. Pope declared, "The automobile will in time be the universal means of transportation, and the future of the American Bicycle Co. rests on the adoption and development of the automobile...I predict that inside of ten years there will be more automobiles in use in the large cities of the United states than there are now horses in these cities" (Flink 1975). Little did he realize that these words predicted an enormous change that has been witnessed throughout 
communities in the United States. In fact, the automobile not only replaced horses, but reshaped cities and even society as a whole. Today, traffic congestion is an overwhelming dilemma facing urban areas around the globe.

The tremendous increase in automobile use in south Florida has been the result of a population explosion compounded by policy decisions allowing untamed development patterns. In addition, as society embarks into the new Millennium, we are faced with the question of how to overcome the growing dependency on oil, which is a finite, natural resource that is supplied mostly by unstable countries in the Middle East. We are also challenged by the increase of air pollution from gases such as $\mathrm{CO}_{2}$ and the growing phenomenon of urban sprawl that is threatening our natural environments that hold fragile ecosystems upon which we depend on for survival.

There are, of course, answers to these intensifying dilemmas. The creation of CAPs in densely populated areas can aid in reducing traffic congestion. These programs can help to reshape society's behavioral patterns to reduce dependency on the automobile and encourage increased usage of alternate forms of transportation such as carpooling, vanpooling and mass transit. CAPs are alternative policy tools that work with the business community to implement TDM initiatives such as preferential parking, developing shuttles, compressed workweeks and telecommuting. While the Florida CAPs are slowly making an impact within their respective communities, they are clearly still maturing, gaining valuable experience in the application of TDM. This study was designed to collect and analyze the experiences of the south Florida CAP so as to facilitate this learning process.

Changes in driving behavior become increasingly necessary when society is experiencing increasing traffic congestion. However, little is usually accomplished before problems reach 
critical points. This, unfortunately, proves that we are a reactive society rather than a proactive one. Nevertheless, CAPs are gaining recognition and are available to educate the public on transportation alternatives and work with the business community on encouraging alternative travel choices. An educated society will realize it needs to become less dependent on the automobile and begin seeking alternatives to move towards a future that will not jeopardize our ability to travel in a sustainable manner! 


\section{List of References}

American Automotive Association. Your Driving Costs 2000. Stock 2717. AAA Association Communication: Heathrow, FL. 2000.

Carrera, Elizabeth. All data and maps were compiled, created and analyzed by the author while working as the Planning Manager for SFCS.

Center for Urban Transportation Research. Performance Measures Report for Gold Coast Commuter Services. University of South Florida, 1997.

Center for Urban Transportation Research. 1997 Gold Coast Commuter Services Evaluation. University of South Florida, 1997.

Center for Urban Transportation Research. Performance Measures Report for South Florida Commuter Services. University of South Florida, 1998.

Center for Urban Transportation Research. 1998 South Florida Commuter Services Evaluation. University of South Florida, 1998.

Center for Urban Transportation Research. Performance Measures Report for South Florida Commuter Services. University of South Florida, 1999.

Center for Urban Transportation Research. 1999 South Florida Commuter Services Evaluation. University of South Florida, 1999.

Center for Urban Transportation Research. Performance Measures Report for South Florida Commuter Services. University of South Florida, 2000.

Center for Urban Transportation Research. 2000 South Florida Commuter Services Evaluation. University of South Florida, 2000.

Center for Urban Transportation Research. Florida Demographics and Journey to Work. University of South Florida, 1993.

Cerny, Thomas. Interview by Author. South Florida Commuter Services. Fort Lauderdale, Florida. 10 July 1999.

Environmental Protection Agency. "Annual Emissions and Fuel Consumption for an Average Passenger Car.” http://www.epa.gov/otaq/ann-emit.htm, 1998.

Ewing, Reid. Transportation and Land Use Innovations: When You Can't Pave Your Way Out of Congestion. Planners Press: Chicago, IL. 1997.

Flynn, Linda. Interview by Author. South Florida Commuter Services. Fort Lauderdale, Florida. 3 May 2000. 
Glazer, Lawrence Jesse. E-mail Interview by Author. ljg@odetics.com. 2 May 2000.

Lee-Cook, Alice. Interview by Author. South Florida Vanpool Program. Miami, Florida. 10 May 2000.

Maurer, Pat. Email Interview by Author.pat@tmi.cob.fsu.edu. Commuter Services of North Florida. Tallahassee, Florida. 16 May 2000.

Murphy, James. Interview by Author. Airport West Transportation Management Initiative. Miami, Florida. 4 May 2000.

Mustard, Bill. Interview by Author. Florida State University Marketing Institute. Tallahassee, Florida. 29 November 2000.

National Cooperative Highway Research Program Report. "Peak-Period Traffic Congestion." National Research Council: Washington D.C. 1976.

National Highway Traffic Safety Administration. “Traffic Safety Facts 1998.” U. S. Department of Transportation, October 1999.

Offord, Bruce. Interview by Author. Florida Department of Environmental Protection. West Palm Beach, Florida. 15 July 1999.

Roach, Bill. E-mail Interview by Author. Bill.Roach@METROKC.GOV. 2 May 2000.

Florida Department of Transportation. Statewide Ridesharing Program Assessment SchimpelerCorradino Associates, February 1988.

Transportation Research Board. "Environmental and Social Effects of Transportation." National Academy Press: Washington D.C. No. 1626, 1998.

Transportation Research Board. "Innovations in Ridesharing." National Research Council: Washington D.C. No. 1082, 1986.

Transportation Research Board. "Transportation Demand Management and Ridesharing." National Academy Press: Washington D.C. No. 1598, 1997.

Trosky, Lisa. Email Interview by Author. bacs@atlantic.com. Bay Area Commuters, Inc. Tampa, Florida. 16 May 2000.

US Census Bureau. Statistical Abstract of the United States. 1999.

US Census Bureau. www.census.gov. 2000.

Widby, Tad. E-mail Interview by Author. Widby@pbworld.com. 5 May 2000. 